\title{
Nucleate Pool Boiling Heat Transfer on Micro-Pin- Finned Surface in Short-Term Microgravity
}

\section{Yonghai Zhang, Jianfu Zhao, Jinjia Wei \& Yanfang Xue}

To cite this article: Yonghai Zhang, Jianfu Zhao, Jinjia Wei \& Yanfang Xue (2016): Nucleate Pool Boiling Heat Transfer on Micro-Pin-Finned Surface in Short-Term Microgravity, Heat Transfer Engineering, DOI: 10.1080/01457632.2016.1200377

To link to this article: http://dx.doi.org/10.1080/01457632.2016.1200377

Accepted author version posted online: 17

Jun 2016.

Published online: 17 Jun 2016.

Submit your article to this journal $₫$

Q View related articles $\asymp$

View Crossmark data \ulcorner 
Nucleate Pool Boiling Heat Transfer on Micro-Pin-Finned Surface in Short-Term Microgravity

\author{
Yonghai Zhang ${ }^{1}$, Jianfu Zhao ${ }^{2}$, Jinjia $\mathrm{Wei}^{1}$, Yanfang Xue ${ }^{1}$ \\ ${ }^{1}$ State Key Laboratory of Multiphase Flow in Power Engineering, Xi'an Jiaotong University, \\ Xi'an, China \\ ${ }^{2}$ Key Laboratory of Microgravity (National Microgravity Laboratory)/CAS, Institute of \\ Mechanics, Chinese Academy of Sciences, Beijing, China \\ Address correspondence to Professor Jinjia Wei, State Key Laboratory of Multiphase Flow in \\ Power Engineering, Xi'an Jiaotong University, Xi'an 710049, China. E-mail: \\ jjwei@mail.xjtu.edu.cn
}




\section{Abstract}

Nucleate boiling heat transfer of air-dissolved FC-72 on micro-pin-finned surface was experimentally investigated in microgravity by utilizing the drop tower facility in Beijing. The dimensions of the silicon chips were $10 \mathrm{~mm} \times 10 \mathrm{~mm} \times 0.5 \mathrm{~mm}$ on which two kinds of micro-pin-fins with the dimensions of $30 \times 30 \times 60 \mu^{3}, 50 \times 50 \times 120 \mu^{3}$ (width $\times$ thickness $\times$ height, named PF30-60, PF50-120) were fabricated by the dry etching technique. The nucleate pool boiling on a smooth surface was also studied under both earth gravity and microgravity for comparison. In general, the micro-pin-fins showed better heat transfer performance when compared with smooth surface, both under earth gravity and microgravity. In microgravity, it is mainly due to the bubbles generated on micro-pin-finned surface can depart from heater surface continuously. For micro-pin-fins, the reduced gravity critical heat flux was about two third of that in earth gravity experiment, but almost three times as large as that for the smooth surface which is larger than that in terrestrial experiment. Under different gravity levels, PF50-120 shows a little better heat transfer than that of PF30-60 mainly due to larger heat transfer area. Besides, fin gap of PF30-60 may generate larger flow resistance for micro-convection around the fin sidewalls, resulting in a lower heat transfer performance. 


\section{INTRODUCTION}

The heat removal devices in space application require not only high efficiency, but also compact size and low energy in particular. Pool boiling is a very efficient means of heat transfer and requires no energy consumption to displace the fluid, and it will be one of the most suitable technologies for heat transfer in space applications since the size and weight of these systems can be reduced greatly. Applications of boiling heat transfer in space can be found in thermal management, fluid handling and control, power systems, on-orbit storage and supply systems for cryogenic propellants and life support fluids, and for cooling of electronic packages associated with various instrumentation and control systems, and so on. In space, the vapor bubble dynamics in pool boiling under microgravity differs considerably from that in terrestrial gravity due to the lack of buoyancy force. Vapor bubbles tend to remain attached or stay in close proximity to the heater surface. Thus, film boiling and burnout can occur in microgravity at a much lower heat flux than that required in terrestrial gravity. As a consequence, the critical heat flux (CHF) of nucleate boiling in microgravity is much lower than that on earth, and the heat transfer capacity declines remarkably. Nevertheless, a stable heat transfer process in space will be required for transferring heat effectively, efficiently and safely with increasing space activities in future.

Boiling heat transfer in microgravity has been the subject of intense research over the past 
five decades. Lee et al. [1] conducted pool boiling experiments using R113 from space flights that provided a gravity level of $10^{-4} g_{0}$ for a period of $280 \mathrm{~s}$. A flat gold film heater $(19 \mathrm{~mm} \times 38$ $\mathrm{mm}$ ) was used. The results demonstrated that there is a steady pool boiling process in microgravity, and heat transfer enhancement in microgravity could be observed only at lower superheats due to early onset of nucleate boiling. They also found that a heat transfer enhancement of up to $40 \%$ was attributed to bubble migration. Thermocapillary convection was thought to be the reason for this kind of motion. Significant deterioration in pool boiling heat transfer was observed at higher superheats under subcooled and saturated boiling conditions. In particular, the saturated boiling heat flux in microgravity was negligible due to a very large coalesced bubble covering the entire heated area. Kim et al. [2] investigated systemically the effect of gravity and subcooling on the boiling heat transfer behavior during pool boiling of FC-72 on a $2.7 \mathrm{~mm} \times 2.7 \mathrm{~mm}$ microheater array using a KC-135 aircraft. Their observation indicated that the boiling heat transfer behavior was dominated by the formation of a large primary bubble on the surface by the coalescence of smaller bubbles under a low- $g$ environment. Besides, dryout occurred under the primary bubble, causing CHF in low-g to be significantly lower than that in earth gravity. Subcooling was also observed to have a strong effect on the size of the primary bubble and on CHF. Pool boiling degassed FC-72 on a flat plate heater ( $28 \mathrm{~mm} \times$ $20 \mathrm{~mm}$ ) aboard the Chinese recoverable satellite SJ-8 was conducted by Zhao and his coworkers $[3,4]$. Their observation revealed that for high subcooling, nucleate boiling and local dry area at 
the base of the coalesced large bubble could co-exist. Besides, they also pointed out that an abrupt transition to film boiling can be observed and an obvious turning point corresponding to $\mathrm{CHF}$ appeared on the boiling curve. It was also shown that heat transfer coefficient and CHF increased with the subcooling or pressure in microgravity, as observed in normal gravity. Experiments of pool boiling of HFE7000 on a flat plate have been performed in both earth and microgravity conditions in parabolic flights by Kannengieser et al. [5]. The results showed that in fully developed boiling regime gravity and subcooling had a weak influence on heat transfer and the superheated liquid layer thickness. Long-term high-quality microgravity pool boiling experiments with FC-72 as the test fluid performed on the International Space Station were reported by Raj et al. [6]. A flat, transparent, constant temperature microheater array was used to perform experiments. Heat transfer was observed to increase with subcooling in both earth and microgravity conditions, the heat transfer throughout the nucleate boiling regime up to CHF was also observed to increase with increasing pressure. Dhir et al. [7] conducted a series of boiling experiments on the International Space Station. The test surface was a polished aluminum disc (1 $\mathrm{mm}$ in thickness, $89.5 \mathrm{~mm}$ in diameter) heated from below with strain gage heaters. The results show that a single bubble continues to grow to occupy the size of the chamber without departing from the heater surface. During lateral merger of bubbles, at high superheats a large bubble may lift off from the surface but continues to hover near the surface. Heat fluxes for steady state nucleate boiling and critical heat fluxes are found to be much lower than those obtained under 
earth normal gravity conditions.

Despite many researchers have done a lot of work that has advanced with the development of the microgravity facilities, the knowledge about the fundamentals of boiling is quite limited and the mechanisms by which the heat is removed from surfaces under these environments are still unclear. Obviously, more work needs to be done to quantify important observations in pursuit of a fundamental understanding of the underlying microgravity effects in both microgravity and earth gravity.

In order to promote the development of new high-efficiency space boiling heat transfer devices, it is very necessary to study the pool boiling with various innovations in microgravity that can provide fundamental information. As is well known, fabricating microstructures on the chip surfaces to generate so-called treated surfaces is an effective method for enhancing boiling heat transfer in terrestrial gravity. Treated surfaces have been found to have great potential in enhancing boiling heat transfer from electronics, significantly reducing the chip surface temperature and increasing CHF. Usually, treated surfaces are used for nucleate boiling enhancement by applying some micro-structures on the chip surface to make the surface capable of trapping vapor and keeping the nucleation sites active or increasing effective heat transfer area. Until now, many kinds of microstructures have been observed, such as microstructured [8], diamond particle [9], micro-re-entrant cavities [10], porous surfaces [11], carbon nanotubes [12], nanowires arrays [13], octagonal micro-posts, or $\mathrm{ZnO}$ nanorods, or both [14], $\mathrm{Cu}$ micro-porous 
surface layers [15] micro-fin arrays covered with porous structure [16], microstructured surfaces with a wide range of well-defined surface roughness [17] and metallic foam surface with crossing and single-directional V-shaped groove [18]. These surfaces can actually enhance boiling heat transfer by increasing nucleate site number and effective boiling heat transfer surface area. Compared with the smooth chip, the boiling curve of the treated surfaces shift toward a smaller wall superheat, with a lower onset temperature of nucleate boiling and a higher critical heat flux. However, the boiling heat transfer is severely deteriorated in the high heat flux region. The reason is that in the high heat flux region, the heater surface is covered with bubbles, which prevent the fresh liquid from reaching the heater surface for evaporation. Wei and his coworkers [19-22] made noticeable progress in nucleate boiling enhancement by using micro-pin-fins $(10-50 \mu \mathrm{m}$ in thickness and $60-270 \mu \mathrm{m}$ in height) which were fabricated on silicon surface using the dry etching technique, and they found that the micro-pin-fins with 30-50 $\mu \mathrm{m}$ in thickness showed better heat transfer performance. It is supposed that the regular interconnected channels formed by the micro-pin-fins can provide a route for fresh liquid supply even at high heat fluxes. The liquid can be driven by capillary force caused by the bubbles staying on the top of micro-pin-fins. The results showed that the boiling curves were almost vertical even in the high heat flux region, the temperature of heated surface decreased, and the heat transfer capacity was improved remarkably.

Following the enhanced boiling heat transfer mechanisms for the micro-pin-finned surfaces, 
it is supposed that although the bubbles staying on the top of the micro-pin-fins cannot detach soon in microgravity, the fresh bulk liquid may still access to the heater surface through interconnect tunnels formed by the micro-pin-fins due to the capillary forces, independent of the gravity level. Therefore, it is of our great interest to study the boiling heat transfer performance of micro-pin-finned surfaces in microgravity. To date no research has been found in the literature that surveyed the effects of micro-pin-fins on boiling heat transfer in microgravity. Wei and his coworkers [23-25] have studied nucleate pool boiling of FC-72 on chip S and PF30-60 under microgravity, and found that the performance of high efficient heat transfer on micro-pin-finned surface due to the sufficient supply of fresh liquid to the heater surface driven by the capillary forces. The present study is a further part of research on pool boiling heat transfer over micro-pin-fins in FC-72 under terrestrial and microgravity conditions, particularly focusing upon the effects of fin size on heat transfer coefficient and CHF of pool boiling in microgravity.

\section{EXPERIMENTAL APPARATUS AND TEST PROCEDURE}

\section{Experimental apparatus}

The pool boiling test facility system designed for conducting drop-tower experiments is shown schematically in Fig. 1. Details of the experimental apparatus can be obtained in our previous studies $[24,25]$.

A P-doped N-type square silicon chip $\left(10 \times 10 \times 0.5 \mathrm{~mm}^{3}\right)$ is used for the heater element. 
Micro-pin-fins are fabricated on the chip surface to enhance boiling heat transfer by using dry etching technique. The fins are $30 \mu \mathrm{m}, 50 \mu \mathrm{m}$ thick and $60 \mu \mathrm{m}, 120 \mu \mathrm{m}$ high respectively (denoted as PF30-60, PF50-120). A smooth chip (denoted as chip S) is also tested for comparison, and the scanning electron microscope (SEM) images of micro-pin-fins are shown in Fig. 2.

\section{Test procedure}

Experiments are conducted under the influence of terrestrial gravity before releasing the drop capsule and then in short-term microgravity during free falling in the drop tower in the National Microgravity Laboratory, Chinese Academy of Sciences, Beijing. The facility satisfied the safety criteria to expose the apparatus in the drop capsule in different gravitational environments varying between microgravity $(\mu g)\left(<10^{-2} g_{0}\right)$ in the free falling period and high-g level in the deceleration recovery system $\left(16 g_{0}\right)$, and $\mu g$ and $g_{0}$ are the gravitational acceleration in microgravity and under terrestrial conditions respectively.

The test chip is heated by setting a constant input current or voltage for the desired heat flux $q$ " to initiate boiling on the heater surface. The high-speed digital camera could work for $8 \mathrm{~s}$ to capture the boiling heat transfer phenomena when an external trigger signal is received. Simultaneously, data measurement and video recording are conducted. As technical reform on the drop tower in Beijing, the experiments are divided into two stages. In the first stage before technical reform, constant direct current method is adopted to heat the silicon chip. After that, in order to attain $\mathrm{CHF}$ in microgravity, the heating method with constant heating voltage is used to 
avoid chip damage. As experimental opportunity limited, only one run is conducted for one heat flux. In addition, to ensure the reproducibility and reliability of the data, identical ground experiments are also conducted for comparison, and the operating conditions are almost identical for both normal gravity and reduced gravity. More detailed procedure can be obtained in our previous studies $[24,25]$.

\section{Experimental conditions}

The detail experimental conditions are summarized in Tables 1-3. Due to the limited experimental opportunity, only one run was conducted for one heat flux. For chip PF30-60, eight run tests under microgravity conditions at eight different heat fluxes respectively are carried out with two heating methods. One is the constant heating current method in the low heat flux region of 7.2-19.4 W/cm ${ }^{2}$ for the first three cases listed in Table 2, another is the constant heating voltage method for the last five cases in Table 2 as heat fluxes exceed $19.4 \mathrm{~W} / \mathrm{cm}^{2}$. We could not control the same temperature condition of working fluid at different experiments, because there is no preheater and no temperature control for working fluid system due to the space limitation of drop tower facility. For chip PF50-120, seven run tests under microgravity conditions at seven different heat fluxes respectively are also carried out with two heating methods. As shown in Table 3, the chip at low heat fluxes of $6.4-10.1 \mathrm{~W} / \mathrm{cm}^{2}$ is heated by the constant heating current method, and the others are heated by the constant heating voltage method. Here, little effect of subcooling is seen in the nucleate boiling regime for micro-pin-finned surface in terrestrial 
experiment in our previous study [20], and liquid subcooling only influences CHF. As mentioned above, due to technical reform on the drop tower in Beijing, the experiments were divided into two stages. The first stage before technical reform adopted constant direct current method for heating silicon chip and liquid subcooling is from $40 \mathrm{~K}$ to $44.5 \mathrm{~K}$. The second stage after technical reform adopted constant direct voltage method for heating silicon chip and liquid subcooling is from $27.2 \mathrm{~K}$ to $32.4 \mathrm{~K}$. For pool boiling heat transfer with micro-pin-finned surface, the natural convective parts of the boiling curves and the transition from natural convection to nucleate boiling region shift to higher heat flux with increasing subcooling in our previous studies [20, 26]. However, the fully developed nucleate boiling curves have only minor variations, but $\mathrm{CHF}$ will increase with increasing liquid subcooling. We also find the same results in the experimental study of pool boiling heat transfer from microporous and square pin-finned surfaces in FC-72 by Rainey et al. [11]. Hence, we can use data points at different liquid subcoolings to make boiling curves for comparison. At the same time, Honda et al. [19], Wei and Honda [20] and Wei [26] compared the boiling curves of degassed and gas-dissolved FC-72 for smooth chip and micro-pin-finned surface. It can be seen that at low heat fluxes just after incipience, the dissolved air significantly enhances heat transfer but the effect diminishes with increasing heat flux similar to that observed for the microporous, square finned surfaces by Rainey et al. [11] and the flat surfaces from Rainey [27]. It indicates that the capillary pumping action is independent of the gas concentration of the working liquid in the moderate and high 
heat flux region, and thus we performed nucleate boiling heat transfer experiments by using the air-dissolved working liquid in present study.

\section{Data reduction and uncertainty analysis}

Heat input through the base of the boiling surface was calculated from the heat flux and the projected area of the heated section $\left(A_{\mathrm{p}}\right)$, as given by Eq. (1).

$$
Q=q " A_{\mathrm{p}}
$$

The heat flux can be calculated by multiplying the heating voltage $U_{\mathrm{H}}$ and heating current $I_{\mathrm{H}}$. The heat transfer coefficient, $h_{\mathrm{v}}$, is then calculated by Eq. (2).

$$
h_{\mathrm{v}}=\frac{q^{\prime \prime}}{T_{\mathrm{w}}-T_{\mathrm{sat}}}
$$

where $T_{\mathrm{w}}$ is the surface temperature and $T_{\text {sat }}$ is the saturation temperature for FC-72.

The uncertainties in chip and bulk liquid temperatures measured by the thermocouples are estimated to be less than $0.3 \mathrm{~K}$. Wall temperature uncertainty may result in errors due to thermocouple calibration by using a platinum resistance thermometer $(0.03 \mathrm{~K})$, temperature correction for obtaining surface temperature based on the measured value at the bottom of the chip $(0.2 \mathrm{~K})$, temperature unsteadiness $(0.1 \mathrm{~K})$ and thermocouple resolution (less than $0.1 \mathrm{~K})$. Heat flux uncertainty is consisted of the errors of electric power per unit area supplied to the chip, heat loss ratio through substrate conduction and transient effect ratio due to the change of internal energy of chip, respectively. Measurement errors of heat voltage $U_{\mathrm{H}}$, current $I_{\mathrm{H}}$ and side length are $0.1 \%, 0.014 \%$ and $0.5 \%$, respectively. The heat loss ratio through substrate is about 
$5.0 \%$ and the transient effect ratio is about $0.3 \%$. So the uncertainty in heat flux is estimated as approximately $6 \%$ for steady boiling heat transfer and $6.3 \%$ for quasi-steady boiling heat transfer. Besides, the experimental uncertainty of the heat transfer coefficient is estimated as approximately $6.0 \%$ for steady boiling heat transfer and $6.3 \%$ for quasi-steady boiling heat transfer.

\section{RESULTS AND DISCUSSION}

\section{Heat transfer coefficient}

Figure 3 shows nucleate boiling heat transfer coefficient and heat flux of micro-pin-fins at different heat fluxes under different gravity levels. The time for entering the microgravity condition is set to $0 \mathrm{~s}$. At low heat fluxes, there is a little increase in the heat transfer coefficient in microgravity, such as heat flux of 6.4 and $10.1 \mathrm{~W} / \mathrm{cm}^{2}$ for PF50-120. Here, the small vapor bubbles generate and attach to the heater surface for a longer time and then coalesced with each other to form a larger bubble which is called the primary bubble, and the primary bubbles are isolated at low heat fluxes, the large space between bubbles and then the thermocapillary convection caused by the temperature gradient along the bubble interface can guarantee the easy access of fresh bulk liquid to the heater surface for the heat transfer. Besides, the primary bubble moves on the surface due to absorption or departs due to g-jitter, liquid rewets the surface, and thus causing an increase in the heat transfer coefficient. g-jitter means fluctuations in the residual 
acceleration. Usually, for spacecraft, g-jitter comes from crew motions, mechanical vibrations (pumps, motors, excitations of natural frequencies of spacecraft structures), spacecraft maneuvers and attitude, atmospheric drag and the earth gravity gradient [28]. For drop tower, g-jitter is mainly comes from atmospheric drag and the earth gravity gradient. Detailed bubble behavior can be found in our previous study $[24,25]$. We can find that the primary bubble oscillated laterally on both smooth surface and micro-pin-finned surface, and allowed rewetting to occur over a portion of the heater surface. The cause of such oscillations is currently unknown, but it may be due to g-jitter or thermocapillary forces, because short-term microgravity environment can provide a low value of residual relative gravity $g / g_{0}\left(10^{-2}-10^{-3}\right)$ and a small g-jitter. Ohta et al. [29] confirmed the both cases of the heat transfer enhancement and the deterioration for nucleate boiling of $\mathrm{CFC} 113$ obtained almost steady state heat transfer during the reduced gravity duration created by MU-300 aircraft under small subcooled conditions. In both cases, bubbles were detached at a very low frequency due to residual gravity or g-jitter, and the possibility to realize the almost steady state heat transfer is strongly dependent on the bubble detachment. Kim et al. [2] thought that the effect of g-jitter must be considered for the low gravity curves. When the primary bubble moves on the surface or departs due to g-jitter, liquid rewets the surface and results in higher wall heat transfer than that observed in a true microgravity environment. Moreover, the heat transfer enhancement of micro-pin-finned surfaces in the low heat flux region is partly due to the dissolved gases. Thus, similar 
enhancements with degassed FC-72 over micro-pin-finned surface will be obtained in microgravity, but the enhancement will decrease. At moderate heat fluxes, the heat transfer coefficient in nucleate boiling was nearly independent of gravity due to continuously detached large bubbles, such as heat flux of $12.5 \mathrm{~W} / \mathrm{cm}^{2}, 19.4 \mathrm{~W} / \mathrm{cm}^{2}$ and $27.9 \mathrm{~W} / \mathrm{cm}^{2}$ for PF30-60 and 19.3 W/cm ${ }^{2}$ and $30.2 \mathrm{~W} / \mathrm{cm}^{2}$ for PF50-120. However, at high heat fluxes, the heat transfer coefficients of PF30-60 and PF50-120 confirmed to be much more sensitive to the gravity reduction as shown in Fig. 3. There is a decrease in the heat transfer coefficient in microgravity. In the high heat flux region, although the large coalesced primary bubble can also depart from the heater surface, the second primary bubbles will cover the heat surface immediately. As a result, the fresh liquid flow in the region between the vapor bubble and the heated surface decreases and there is drying of the microlayer, and thus causing a decrease in the heat transfer coefficient. In general, the increase or decrease in the heat transfer coefficient under microgravity is limited to $\pm 30 \%$, and the heat transfer coefficient under microgravity always decreases with increasing heat flux, which is consistent with the conclusions of Straub [30]. For the heat flux for 43.6 W/ $/ \mathrm{cm}^{2}$ of PF30-60, we can found that boiling heat transfer in microgravity is severely deteriorated as compared with that in normal gravity. Due to the constant heating voltage method, surface temperature will increase sharply when heat transfer is severely deteriorated, and the resistance of silicon chip will increase which lead to a decline in heat flux as show in Fig. 3. Hence, the heat transfer coefficient decreases sharply. 
Because of limited opportunity of experiments in microgravity, it is necessary to find a correlation to accurately predict pool boiling heat transfer coefficient of micro-pin-fins in microgravity. In Fig. 4 the results for the heat transfer coefficient $\left(h_{\mathrm{v}}\right)$ as a function of the heat flux $(q ")$ are shown. For micro-pin-fins in microgravity, the heat transfer coefficient increases linearly with increasing heat flux in the low and moderate heat flux regions. At high heat fluxes, the heat transfer coefficient decreases with an increase in the heat flux as shown in Fig. 4. This trend is familiar with the results of Di Marco and Grassi [31]. They pointed that boiling heat transfer in microgravity is severely degraded, this is due to the fact that the vapor patch is no more periodically hovered from the surface at high heat fluxes. As shown in Fig. 4, the data are well fitted for low values of the heat flux by the correlation proposed in the VDI Heat Atlas [32]. In the 1993 English version edition of the Heat Atlas, it has been shown that experimental data for a large number of fluids are correlated successfully by Eqs. (3) and (4). The reference conditions are chosen to be typical mid-range values for fully developed nucleate boiling in industrial applications: $q "=2 \mathrm{~W} / \mathrm{cm}^{2}$. The reference state for the heater is defined as a copper cylinder with an intermediate value of $0.4 \mathrm{~mm}$ of the arithmetic mean roughness height of the surface (as defined in ISO 4287/1:1984), which lies within the range common for heater surfaces manufactured in practice.

$$
h_{\mathrm{v}}=h_{\mathrm{re} \mathrm{e}}\left(\frac{q "}{q "_{\mathrm{re} \mathrm{t}}}\right)^{n}
$$




$$
n=0.9-0.3\left(\frac{P_{\mathrm{s}}}{P_{\text {crit }}}\right)^{0.3}
$$

In our study, $n=0.837$ for FC-72 $\left(P_{\text {crit }}=18.3 \mathrm{MPa}\right)$, and of $h_{\text {ref }}$ and $q "$ ref are reference values, to be determined empirically $\left(19.3 \mathrm{~W} / \mathrm{cm}^{2}\right.$ in the present case). The predicted heat transfer coefficient results can be obtained with the coefficient $n$ given by the correlation $(n=0.837)$ at low and moderate heat fluxes (from 6.4 to $34.3 \mathrm{~W} / \mathrm{cm}^{2}$ ) of PF30-60 and PF50-120 under both normal gravity and microgravity, which $90 \%$ of data were predicted within $\pm 15 \%$. Di Marco and Grassi [31] used VDI correlation to predict heat transfer coefficient of smooth surface in normal gravity, and $99 \%$ of data were predicted within $\pm 6 \%$ with $q "{ }_{\text {ref }}=10 \mathrm{~W} / \mathrm{cm}^{2}$. For the prediction results in microgravity, all the data were predicted within $\pm 15 \%$ with the coefficient $n$ given by the correlation $(n=0.45)$ at low and moderate heat fluxes which are less than $13.6 \mathrm{~W} / \mathrm{cm}^{2}$. So VDI correlation can be used to predict pool boiling heat transfer coefficient of micro-pin-fins well in microgravity at low and moderate heat fluxes.

\section{Boiling curves}

Figure 5 shows boiling heat transfer curves of chip PF30-60 and PF50-120 under different gravity levels at atmosphere pressure. The boiling curves of chip S under different gravity levels [24] and other data reported in the literatures [3, 6, 33] are also shown for comparison. For micro-pin-fins and chip S in Fig. 5, the boiling curve is not a complete one in normal gravity, and the CHF point was not displayed on the curve. We just showed the heat flux values of test runs point to point before and after entering microgravity. $\Delta T_{\text {sat }}$ represents wall superheat which is the 
difference between $T_{\mathrm{w}}$ and $T_{\text {sat }}$. The heat flux is calculated by the heating voltage $U_{\mathrm{H}}$ and heating current $I_{\mathrm{H}}$. For $U_{\mathrm{H}}, I_{\mathrm{H}}$ and $T_{\mathrm{w}}$, which are calculated by the arithmetic mean of the data during the normal gravity period of $-4-0 \mathrm{~s}$ before drop and microgravity period of 1-3.6 $\mathrm{s}$ after drop, because the data at this time remains nearly constant. However, for the last data point of micro-pin-fins and chip $\mathrm{S}$ in microgravity, the wall temperature is the value by the end of the 3.6 $\mathrm{s}$ period due to its continuous rising in the whole period of $3.6 \mathrm{~s}$.

As is well known, the bubble behaviors are very different from each other between earth gravity and microgravity due to the lack of buoyancy force under microgravity condition. However, we can see that micro-pin-fins (PF30-60 and PF50-120) still show a large enhancement on boiling heat transfer compared with all the flat plate surfaces in microgravity from Fig. 5. For micro-pin-fins, compared with terrestrial experiment, under the low heat flux conditions, vapor bubbles increase in size and are still attached to heater surface throughout the entire microgravity period. However, the wall temperature is a little lower than that in normal gravity, such as PF30-60 at $7.2 \mathrm{~W} / \mathrm{cm}^{2}$, PF50-120 at $6.4 \mathrm{~W} / \mathrm{cm}^{2}$ and $10.1 \mathrm{~W} / \mathrm{cm}^{2}$, showing an enhancement of the heat transfer process in microgravity. Under the moderate heat flux conditions, with increase in heat flux, the number of vapor bubbles as well as their size significantly increases, the transition between low and high heat flux regions can be observed, and the wall temperature of chip is nearly constant at different gravity levels. Moreover, coalescence occurs continuously among adjacent bubbles and the large coalesced bubble engulfs 
the small bubbles around it, resulting in the large coalesced bubble's departure from the heater surface eventually. At high heat fluxes, although the large coalesced bubble can also depart from the heater surface and the wall temperature is a little bit higher than that in normal gravity, it indicates that boiling heat transfer in microgravity is deteriorated as compared with that in normal gravity. Moreover, a nucleate boiling heat transfer enhancement surface made by thermal spraying in microgravity has been studied by Asano et al. [34]. They studied the effect of gravity on boiling heat transfer with smooth surface and treated surface during parabolic trajectory flight of an airplane, and the copper was used as coating material. Pool boiling experiments in saturated liquid of HCFC123 were carried out for heat fluxes between 1.0 and $10 \mathrm{~W} / \mathrm{cm}^{2}$ and saturated temperature of $30{ }^{\circ} \mathrm{C}$. The results showed that heat transfer enhancement by thermal spray coating could be obtained under $\mu g$ as the same as that under earth gravity in the range of low and moderate heat fluxes, which are consistent with experiment results, but they considered that the high heat transfer performance of thermal spray coating surface might be due to the high wettability.

For the present data of chip $\mathrm{S}$, the last data point with the highest heat flux is not the value of the steady state due to the short duration of microgravity, and then a dashed line was used to connect it with the other data points. As illustrated above, Honda et al. [19] and Wei and Honda [20] compared the boiling curves of degassed and gas-dissolved FC-72 for smooth chip and micro-pin-finned surface. The gas-dissolved FC-72 showed a marked decrease in the boiling 
incipience temperature, and just after incipience, the dissolved air significantly enhances heat transfer but the effect diminishes with increasing heat flux. Thus, the boiling incipience temperature of chip $\mathrm{S}$ in our study is much lower than the other researcher's result due to higher liquid subcooling and gas-dissolved working fluid. It can be clearly seen that heat transfer was observed to increase with subcooling at both earth and microgravity conditions for all flat plates as shown in Fig. 5. This agrees with the results of studies made by Lee et al. [1] and Raj et al. [6].

Moreover, O'connor et al. [9] conducted boiling experiments for a $10 \mathrm{~mm}$ square horizontally mounted smooth copper surface immersed in a pool of FC-72. Since their experimental conditions are very close to the previous experimental study [26], here the boiling curves were compared indirectly with our previous experimental data for a smooth silicon surface, as shown in Fig. 6. We can clearly see that our boiling curves are very close to those obtained by O'connor et al. [9] for the liquid subcoolings of $0 \mathrm{~K}, 25(20) \mathrm{K}$ and 45(40) K. Thus, the boiling curves will agree well with each other and can be compared with each other if the experimental conditions are nearly same. Obviously, in Fig. 5, results of flat plate surfaces from previous researches are different from those of the smooth surface used in our research. It is because that the liquid subcoolings are different from each other. With increasing liquid subcooling, pool boiling curves will shift to left and the CHF will increase. For micro-pin-fins and chip S in Fig. 5, the boiling curve is not a complete one in normal gravity, and the CHF point 
was not displayed on the curve. We just showed the heat flux values of test runs point to point before and after entering microgravity. The complete boiling curves can be seen in Fig. 9 later. The boiling curve of chip $\mathrm{S}$ in our study shows highest CHF in normal gravity due to highest liquid subcooling. In microgravity, the results of smooth surfaces are a little different from each other which may be due to difference in gravity levels, heat methods and heater geometries, but the overall trend is obviously, that heat transfer is enhanced in the low heat flux region and deteriorated in the high heat flux region. Besides, from Fig. 5, we can see that the present result of smooth surface is consistent with those of Zhao et al. [3], Raj et al. [6] and Di Marco and Grassi [31], and that the slopes of the heat transfer curves decrease in the high heat flux region in microgravity. It is attributed to that the higher superheats as the primary bubble causes dryout over a successively larger fraction of the heater at high heat fluxes, which causes an obvious deterioration of the heat transfer process in microgravity. Furthermore, the results of Zhao et al. [3] in microgravity changes greatly from that in normal gravity and the slopes of the heat transfer curves in microgravity are much lower than the others as shown in Fig. 5, which may be caused by the quasi-steady heating method used by Zhao et al. [3].

\section{CHF results}

For chip S and micro-pin-fins, experiments were only conducted near CHF conditions, but did not capture the CHF exactly because of the difficulties to obtain the data under limited duration of reduced gravity conditions. Figures 7 and 8 show variations of the bubble behavior, 
surface temperature, heat voltage and gravity of the last experimental point for chip $\mathrm{S}$ and micro-pin-finned surfaces under different gravity levels. The positions of Figs. 7(a)-(d) are marked on the curve of the mean heater surface temperature shown in Fig. 8. It can be clearly seen that vapor bubbles experience very remarkable change with the reduction of gravity and the increase of time in microgravity. For chip $\mathrm{S}$ with increasing time up to $1.6 \mathrm{~s}$, a coalesced large bubble forms and tends to maintain a hemispherical dome shape with a large contact area on the heater surface, causing continuously increase in wall temperature as shown in Fig. 8. With further increasing time up to $3.0 \mathrm{~s}$, the large bubble gradually shrinks to smooth in contour due to the highly subcooled condensation and covers the heater surface completely in microgravity for chip S. However, for PF30-60, the large bubble formed rapidly (0.12s) after entering microgravity environment as shown in Fig .7, and the large bubble gradually shrinks to an oblate in shape with smooth contour due to the highly subcooled condensation at the bubble cap with increasing time up to $1.6 \mathrm{~s}$, and then the size becomes larger with further increasing time to $3.0 \mathrm{~s}$. For chip S and PF30-60, the bubbles attached to the heater surface during the whole microgravity period as shown in Fig. 7. The full coverage of the large bubble on the heater surface prevents the fresh bulk liquid from accessing the heating surface for evaporation heat transfer, making the removal of heat flux very difficult and leading to an obvious increase of the mean heater surface temperature and deterioration of boiling heat transfer, as is observed in Fig. 8. Thus, the CHF results can be obtained for chip S and PF30-60 as shown in Fig. 9. 
For PF50-120, the small bubbles on the heater surface are very vigorous to coalesce with each other to form a large bubble very quickly after entering microgravity $(0.12 \mathrm{~s})$. With time increasing, large spherical bubble is formed and almost completely covers the heater surface, and then the large spherical bubble starts to depart from the heater surface, and another new large bubble is going to generate as shown in Fig. 7. The wall temperature of the PF50-120 does not increase sharply as chip S and PF30-60, but still increases to a little higher value after entering microgravity as shown in Fig. 8, which indicating unsteady nucleate boiling state. Thus, we speculated that this point is close to the CHF point of PF50-120 in microgravity.

Figure 9 shows boiling curves for chips $\mathrm{S}$ and micro-pin-fins in different gravity levels. We can see that the reduced gravity CHF of micro-pin-fins was estimated to be about at least two third of that at the same condition in terrestrial experiment, and the reduced gravity CHF of Chip $\mathrm{S}$ was estimated to be about $40-50 \%$ of that in terrestrial experiment. But, the reduced gravity CHF of micro-pin-fins are almost three times as large as that for the smooth surface which is larger than that in terrestrial experiment. Moreover, the reduced gravity CHF of micro-pin-fins is much higher than that of other flat plate surfaces with same working fluid shown in Table 4 [1-3, $6,35,36]$. The primary reason is that although the micro-pin-finned surface is covered with large mushroom bubble in the high heat flux region, the strong capillary force generated by the interface between the large mushroom bubble and the liquid of the microlayer beneath the large mushroom bubble drives plenty of fresh liquid into contact with the superheated wall for 
vaporization through the regular interconnected structures formed by the micro-pin-fins. Thus, the sufficient supply of bulk liquid to the heater surface guarantees the continuous growth of the large mushroom, which also enhances the micro-convection heat transfer by the motion of liquid around the micro-pin-fins, and leads to CHF enhancement.

It is well known that critical heat flux plays a key role in nucleate boiling heat transfer and it represents the capacity of maximum heat dissipation. It has been reported that there are two fundamental approaches to enhance boiling heat transfer in terrestrial experiments: developing enhanced boiling surfaces and developing new working fluids. Recently, many researchers have investigated these two enhanced boiling heat transfer methods in microgravity. In the following, highlights of the pool boiling experimental activities carried out in this field by some teams are given. Their main features are summarized in Table $4, q{ }{ }_{\mathrm{CHF}-1 \mathrm{~g}}$ and $q{ }{ }_{\mathrm{CHF}-\mu \mathrm{g}}$ represent the critical heat flux in normal gravity and microgravity respectively. The critical heat flux (CHF) results or the heat flux near CHF for different flat plate surfaces and working fluids in pool boiling heat transfer under microgravity condition can be gained. We can obtain from Table 4 that the CHF for all liquids in microgravity is considerably smaller than in normal gravity, but the degree of reduction is different. The effect of gravity on critical heat flux is one of the most important subjects but very few results were obtained because of the difficulties to obtain the data under the limited duration of reduced gravity. 


\section{Effect of micro-pin-fins}

Figure 10 shows the bubble behavior of chip S and micro-pin-finned chips at similar low heat fluxes under different gravity levels. It can be found that before entering the microgravity condition, the bubbles generate and departure continuously from the heater surface at a steady state due to the effects of buoyancy forces for both chip $\mathrm{S}$ and micro-pin-fins. The bubble number for chip PF50-120 is much larger than that for the smooth chip in earth gravity, indicating that the micro-pin-finned surface can provide a larger number of nucleation sites for enhancing boiling heat transfer performance. As shown in Fig. 10, after entering microgravity condition, due to the weakness of the buoyancy force, the small bubbles generate and coalesce with each other to form larger bubbles which are attached to the heater surface during the whole microgravity period except for one bubble at the time $3.2 \mathrm{~s}$. Although the bubble behaviors are almost similar between chip S and micro-pin-fins, the details are quite different. For both chip S and micro-pin-fins, the coalesced bubbles become larger and larger with increasing heat flux, but the coalesced bubbles for the micro-pin-finned chip are much smaller than that of the smooth chip for nearly same range of heat fluxes, and the numbers of large coalesced bubbles are larger than that of the smooth chip as shown in Figs. 10 (a)-(c). With time increasing for chip S, the hemispherical coalesced bubble becomes bigger and bigger and covers the whole heating surface, especially at the heat flux of $11.59 \mathrm{~W} / \mathrm{cm}^{2}$, and thus blocks the access of fresh liquid for evaporation. As a consequence, the mean heater surface temperature increases gradually, and the 
boiling heat transfer in microgravity is deteriorated as compared to that in normal gravity. However, for PF30-60 and PF50-120, heat transfer enhancement can be obtained in microgravity according to boiling curves as shown in Fig. 9. This is probably caused by the evaporation of the larger liquid microlayer areas formed beneath the vapor bubbles in microgravity. The ratios of micro-pin-finned surface area to smooth surface area are 3.0 and 3.4 for chips PF30-60 and PF50-120, respectively. The parameters of micro-pin-fins are shown in Table 5. At low heat fluxes, after nucleate boiling is initiated, the active sites are only a few and widely separated at low wall superheat levels, and it is referred to the isolated bubble regime. Nucleate boiling may be initiated at the fin root due to high temperature on the fin root. This may result in a section of the fin (near the root) cooled by nucleate boiling, and the rest cooled by single-phase convection. Thus, an increase in total heat transfer area duo to the existence of side walls of micro-pin-fins is considered to be primary reason for heat transfer enhancement in the isolated bubble regime. Besides, PF50-120 show better heat transfer performance than that of PF30-60 due to larger heat transfer area.

Figure 11 shows the bubble behavior of PF30-60 and PF50-120 at similar moderate and high heat fluxes which is referred to the regime of slugs and columns under different gravity levels. In earth gravity, with increasing heat flux, more and more sites become active, and the bubble frequency at each site generally increases. Eventually the active sites are spaced so closely that bubbles from adjacent sites merge together during the final stages of growth and 
release. Vapor is being produced so rapidly that bubbles merging together form columns of vapor slugs that rise upward in the liquid pool towards its free surface as shown in Fig. 11. After entering microgravity condition, bubble departure frequency shows an obvious decrease due to lack of buoyancy force. Thus, primary bubbles, slugs and columns grow much larger than that in earth gravity for both PF50-120 and PF30-60 as shown in Figs. 11(a)-(d), and the bubble behaviors are quite similar with each other. Here, an increase in total heat transfer area is also a reason for heat transfer enhancement but not the primary reason. The primary reason is that the capillary force generated by the bubbles drives plenty of fresh liquid into contact with the superheated wall for vaporization through the regular interconnected structures formed by micro-pin-fins, as well as improves the micro-convective heat transfer by the motion of liquid around the micro-pin-fins. The optimum fin height, $h$ and fin gap, $p$ are determined by the balance between the capillary force and the flow resistance for micro-convection. Besides, careful observation of boiling curves between chips PF50-120 and PF30-60 as shown in Fig. 9 reveal that although the former has larger $h / p$ than the latter, the slopes are a little smaller for both earth gravity and microgravity. It is considered that the fin gap of chip PF30-60 may generate larger flow resistance for micro-convection around the fin sidewalls, resulting in a lower heat transfer performance than that of chip PF50-120. The $q$ " ${ }_{\text {CHF-1g }}$ of chip PF50-120 is higher than that of chip PF30-60, but $q{ }^{\prime}{ }_{\mathrm{CHF}-\mu \mathrm{g}}$ of chip PF50-120 and PF30-60 are nearly same with each other. It means the size of micro-pin-fins have little effect on $q "{ }_{\text {CHF- } \mu \mathrm{g}}$ in the present 
study.

In microgravity, micro-pin-finned surfaces show better heat transfer performance compared with smooth surface, especially in the moderate and high heat flux regions, and show higher CHF than that of chip S. It is mainly due to the bubbles generated on micro-pin-finned surface can depart from heater surface continuously in microgravity. The heat transfer mechanisms of micro-pin-fins in microgravity can be speculated as follows:

Firstly, for micro-pin-fins at high heat fluxes, the heater surface is covered by the large mushroom bubble as shown in Fig. 12. However, The capillary force generated by the interface between the large bubble and the liquid of the microlayer beneath the bubble drives plenty of fresh liquid to contact with the superheated wall for vaporization through the regular interconnected structures formed by the micro-pin-fins, as well as improves the micro-convection heat transfer by the motion of liquid around the micro-pin-fins, as shown schematically in Fig. 12. Therefore, there is no deterioration of boiling heat transfer performance for the micro-pin-finned surface. The sufficient supply of bulk liquid to the heater surface guarantees the continuous growth of the large bubble. When the bubble size grows up to a certain value, the bubble departs away from the heater surface. With increasing heat flux, the capillary force cannot overcome hydraulic drag force between micro-pin-fins, which leads to the fresh liquid blocked. As a result, the liquid near some micro-pin-fins is used up due to shortage of fresh liquid supply, which leads to the increase of wall temperature with partial dryout, and 
reaches $\mathrm{CHF}$ at last.

Secondly, in our previous study [37], the forces acting on a growing bubble were analyzed.

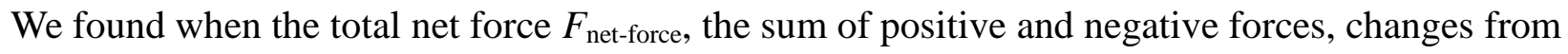
negative to positive, the bubble begins to detach from the heater surface. Detailed analysis process can be found in our previous study [37]. By using the new force balance model, the prediction values of the bubble departure radius from micro-pin-fins are all about $3 \mathrm{~mm}$. It indicates that the bubble should depart from the heater surface when the bubble radius is larger than $3 \mathrm{~mm}$. However, bubble coalescence in vertical and horizontal directions become more intensely at high heat fluxes, and thus delays the bubble detachment. In this process, the total net force $F_{\text {net-force }}>0$. The primary bubble grows larger gradually and there are a lot of smaller bubbles around the primary bubble as shown in Fig. 13(a). The thermocapillary flow can drive the bubbles staying on the top of the micro-pin-fins to coalesce with the primary bubble as shown in Fig. 13(b). Therefore, the small bubbles form connections between the primary bubble and the heated surface to prevent the primary bubble from departing, resulting in an additional

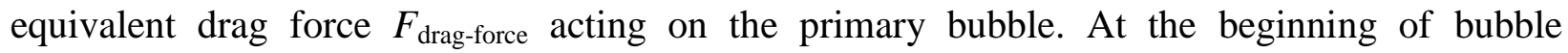
coalescence, $F_{\text {net-force }}-F_{\text {drag-force }}<0$, thus the primary coalesced bubble can not depart from the heater surface. As primary bubble grows larger gradually mainly by absorbing small bubbles, $F_{\text {net-force }}$ also becomes larger. Until the total net force acting on the primary bubble is large enough to overcome the additional drag force by small bubbles, $F_{\text {net-force }}-F_{\text {drag-force }}>0$, the 
primary bubble can depart from the heater surface. Thus, micro-pin-finned surface can supply enough fresh liquid to guarantee that the bubble can grow up to the departure size. For smooth surface, it cannot supply enough fresh liquid for bubble growth, and thus only few bubbles can depart from heater surface, and reach CHF at low heat fluxes compared with micro-pin-fins.

Thirdly, as shown in Fig. 14, the large bubble coalescence in vertical direction can accelerate the bubble detachment, and thus the heat can be taken away from heater surface in time which is good for the heat transfer. For smooth surface, the large bubble coalescence in vertical direction was not found due to few departure bubbles in microgravity.

\section{CONCLUSIONS}

Enhanced subcooled pool boiling heat transfer over micro-pin-finned surface from a square silicon chip $\left(10 \times 10 \times 0.5 \mathrm{~mm}^{3}\right)$ of air-dissolved FC-72 under both earth gravity and microgravity were conducted. The nucleate pool boiling on a smooth surface was also studied from the perspectives of both earth gravity and microgravity for comparison, and the following conclusions can be obtained:

(1) The boiling heat transfer on the micro-pin-finned surface in microgravity showed better performance than that of smooth surface, which stems from the sufficient supply of fresh liquid to heater surface due to the capillary driving force caused by a bubble hovering on the top of micro-pin-fins. Since the capillary force is not related to the gravity level, the micro-pin-finned surface appears to be one promising enhanced surface not only in normal gravity but also under 
microgravity conditions, which is very helpful to reduce the cooling system weight in space and in planetary neighbors.

(2) For micro-pin-fins, at low heat fluxes, there is a little increase in the heat transfer coefficient in microgravity. At moderate heat fluxes, the heat transfer coefficient in nucleate boiling was nearly independent of gravity due to continuously detached large bubbles. At high heat fluxes, the heat transfer coefficients confirmed to be much more sensitive to the gravity reduction, and there is a decrease in the heat transfer coefficient in microgravity.

(3) For micro-pin-fins, the reduced gravity CHF of micro-pin-fins was estimated to be about at least two third of that at the same condition in terrestrial experiment which is significantly higher than that observed using a smooth chip with same working fluid, and the reduced gravity CHF of Chip S was estimated to be about $40-50 \%$ of that in earth gravity. But, the CHF of micro-pin-fins in microgravity are almost three times as large as that for the smooth surface which is larger than that in terrestrial experiment. Besides, the sizes of micro-pin-fins have little effect on $q{ }^{\prime C H F-\mu g}$ in present study.

(4) Bubble behaviors of PF30-60 and PF50-120 in the isolated bubble regime and the regime of slugs and columns are quite similar with each other. PF50-120 show a little better heat transfer than that of PF30-60 due to larger heat transfer area under both earth gravity and microgravity. The optimum fin height, $h$ and fin gap, $p$ are determined by the balance between the capillary force and the flow resistance for micro-convection. It is considered that the fin 
gap of chip PF30-60 may generate larger flow resistance for micro-convection around the fin sidewalls, resulting in a lower heat transfer performance than that of chip PF50-120.

\section{ACKNOWLEDGMENTS}

This work is supported financially by the National Natural Science Foundation of China under the grants of 51225601, 51506169 and 11372327, and the Key Laboratory of Microgravity, Institute of Mechanics, Chinese Academy of Sciences for short-term microgravity experiments utilizing the Drop Tower Beijing. Besides, it is also supported by the scientific research program for new lecturer of Xi'an Jiaotong University (No.DW010728K000000B) and China Postdoctoral Science Foundation funded project (No.2015M582653). 


\section{NOMENCLATURE}

$A_{\mathrm{p}} \quad$ projected area of the heated section, $\mathrm{m}^{2}$

CHF critical heat flux

$F_{\text {net-force }}$ net force acting on the bubble, $\mathrm{N}$

$F_{\text {drag-force }}$ drag force acting on the bubble, $\mathrm{N}$

$g$ gravitational acceleration at the microgravity condition, $\mathrm{m} / \mathrm{s}^{2}$

$g_{0} \quad$ gravitational acceleration at the terrestrial condition, $\mathrm{m} / \mathrm{s}^{2}$

$h \quad$ fin height, $\mu \mathrm{m}$

$h_{\text {ref }} \quad$ reference heat transfer coefficient, $\mathrm{W} / \mathrm{m}^{2} \cdot \mathrm{K}$

$h_{\mathrm{v}} \quad$ heat transfer coefficient, $\mathrm{W} / \mathrm{m}^{2} \cdot \mathrm{K}$

$I_{\mathrm{H}} \quad$ heating current, $\mathrm{A}$

n constant

$p \quad$ fin pitch, $\mu \mathrm{m}$

$P_{\mathrm{s}} \quad$ system total pressure, $\mathrm{kPa}$

$P_{\text {crit }} \quad$ critical pressure of FC-72, $\mathrm{kPa}$

$Q \quad$ input electric power, W

$q " \quad$ heat flux, $\mathrm{W} / \mathrm{cm}^{2}$

$q{ }^{\prime}{ }_{\mathrm{CHF}-1 \mathrm{~g}}$ critical heat flux in normal gravity, W/cm ${ }^{2}$

$q{ }{ }_{\mathrm{CHF}-\mu \mathrm{g}}$ critical heat flux in microgravity, W/cm ${ }^{2}$ 


\section{ACCEPTED MANUSCRIPT}

$q "$ ref $\quad$ reference heat flux, $\mathrm{W} / \mathrm{cm}^{2}$

SEM scanning electron microscope

$t \quad$ fin thickness, $\mu \mathrm{m}$ or time, $\mathrm{s}$

$T_{\mathrm{b}} \quad$ temperature of bulk liquid, ${ }^{\circ} \mathrm{C}$

$T_{\text {sat }} \quad$ saturation temperature, ${ }^{\circ} \mathrm{C}$

$T_{\mathrm{w}} \quad$ wall temperature, ${ }^{\circ} \mathrm{C}$

$U_{\mathrm{H}} \quad$ heating voltage, $\mathrm{V}$

$w \quad$ fin width, $\mu \mathrm{m}$

Greek symbols

$\Delta T_{\text {sat }} \quad$ wall superheat $\left(=T_{\mathrm{w}}-T_{\text {sat }}\right), \mathrm{K}$

$\Delta T_{\text {sub }} \quad$ liquid subcooling $\left(=T_{\text {sat }}-T_{\mathrm{b}}\right), \mathrm{K}$ 


\section{REFERENCES}

[1] Lee, H. S., Merte, H., and Chiaramonte, F., Pool boiling curve in microgravity, Journal of Thermophysics and Heat Transfer, vol. 11, no. 2, pp. 216-222, 1997.

[2] Kim, J., Benton, J., and Wisniewski, D., Pool boiling heat transfer on small heaters: effect of gravity and subcooling, International Journal of Heat and Mass Transfer, vol. 45, no. 19, pp. 3919-3932, 2002.

[3] Zhao, J. F., Li, J., Yan, N., and Wang, S. F., Bubble behavior and heat transfer in quasi-steady pool boiling in microgravity, Microgravity Science and Technology, vol. 21, pp. S175-S183, 2009.

[4] Zhao, J. F., Two-phase flow and pool boiling heat transfer in microgravity, International Journal of Multiphase flow, vol. 36, no. 2, pp. 35-143, 2010.

[5] Kannengieser, O., Colin, C., and Bergez, W., Influence of gravity on pool boiling on a flat plate: Results of parabolic flights and ground experiments, Experimental Thermal and Fluid Science, vol. 35, no. 5, pp. 788-796, 2011.

[6] Raj, R., Kim, J., and McQuillen, J., Pool boiling heat transfer on the international space station: experimental results and model verification, Journal of Heat Transfer, vol. 134, pp. 10154-1-14, 2012.

[7] Dhir, V. K., R·Warrier, G., Aktinol, E., Chao, D., Eggers, J., Sheredy, W., and Booth, W., Nucleate Pool Boiling Experiments (NPBX) on the international space station, Microgravity 
Science and Technology, vol. 24, no. 5, pp. 307-325, 2012.

[8] Anderson, T. M., and Mudawar, I., Microelectronic cooling by enhanced pool boiling of a dielectric fluorocarbon liquid, ASME Journal of Heat Transfer, vol. 111, no. 3, pp. 752-759, 1989.

[9] O’Connor, J. P., You, S. M., and Chang, J. Y., Gas saturated pool boiling heat transfer from smooth and microporous surfaces in FC-72, ASME Journal of Heat Transfer, vol. 118, no. 3, pp. 662-667, 1996.

[10] Kubo, H., Takamatsu, H., and Honda, H., Effects of size and number density of micro-reentrant cavities on boiling heat transfer from a silicon chip immersed in degassed and gas dissolved FC-72, Journal of Enhanced Heat Transfer, vol. 6, pp. 151-160, 1999.

[11]Rainey, K. N., You, S. M., and Lee, S., Effect of pressure, subcooling, and dissolved gas on pool boiling heat transfer from microporous, square pin-finned surfaces in FC-72, International Journal of Heat and Mass Transfer, vol. 46, no. 1, pp. 23-25, 2003.

[12] Ujereh, S., Fisher, T., and Mudawar, I., Effects of carbon nanotube arrays on nucleate pool boiling, International Journal of Heat and Mass Transfer, vol. 50, no.19-20, pp. 4023-4038, 2007.

[13]Chen, R., Lu, M. C., Srinivasan, V., Wang, Z. J., Cho, H. H., and Majumdar, A., Nanowires for enhanced boiling heat transfer, Nano Letters, vol. 9, no. 2, pp. 548-553, 2009.

[14] Kim, S., Kim, H. D., Kim, H. Kim, Ahn, H. S., Jo, H., Kim, J., and Kim, M. H., Effects of 
nano-fluid and surfaces with nano structure on the increase of CHF, Experimental Thermal and Fluid Science, vol. 34, no. 4, pp. 487-495, 2010.

[15]El-Genk, M. S., and Ali, A. F., Enhanced nucleate boiling on copper micro-porous surfaces, International Journal of Multiphase Flow, vol. 36, no.10, pp. 780-792, 2010.

[16] Pastuszko, R., Pool boiling on micro-fin array with wire mesh structures, International Journal of Thermal Sciences, vol. 49, no. 12, pp. 2289-2298, 2010.

[17]Chu, K. H., Enright, R., and Wang, E. N., Structured surfaces for enhanced pool boiling heat transfer, Applied Physics Letters, vol. 100, no. 24, pp. 241603-1-4, 2012.

[18]Qu, Z. G., Xu, Z. G.., Zhao, C. Y., and Tao, W.Q., Experimental study of pool boiling heat transfer on horizontal metallic foam surface with crossing and single-directional V-shaped groove in saturated water, International Journal of Multiphase Flow, vol. 41, pp. 44-55, 2012.

[19] Honda, H., Takamastu, H., and Wei, J. J., Enhanced boiling of FC-72 on silicon chips with micro-pin-fins and submicron-scale roughness, Journal of Heat Transfer, vol. 124, no. 2, pp. 383-390, 2002.

[20] Wei, J. J., and Honda, H., Effects of fin geometry on boiling heat transfer from silicon chips with micro- pin-fins immersed in FC-72, International Journal of Heat and Mass Transfer, vol. 46, no. 21, pp. 4059-4070, 2003.

[21] Honda, H., and Wei, J. J., Enhanced boiling heat transfer from electronic components by use 
of surface microstructures, Experimental Thermal and Fluid Science, vol. 28, no. 2-2, pp.159-169, 2004.

[22] Wei, J. J., Guo, L. J., and Honda, H., Experimental study of boiling phenomena and heat transfer performances of FC-72 over micro-pin-finned silicon chips, Heat and Mass Transfer, vol. 41, no. 8, pp. 744-755, 2005.

[23] Wei, J. J., Xue, Y. F., Zhao, J. F., and Li, J., Bubble behavior and heat transfer of nucleate pool boiling on micro-pin-finned surface in microgravity, Chinese Physics Letters, vol. 28, no. 1, pp. 016401/1-4, 2011.

[24]Xue, Y. F., Zhao, J. F., Wei, J. J., Li, J., Guo, D., and Wan, S. X., Experimental study of nucleate pool boiling of FC-72 on smooth surface under microgravity, Microgravity Science and Technology, vol. 23, no. 1, pp. S75-S85, 2011.

[25] Xue, Y. F., Zhao, J. F., Wei, J. J., Zhang, Y. H., and Qi, B. J., Experimental study of nucleate pool boiling of FC-72 on micro-pin-finned surface under microgravity, International Journal of Heat and Mass Transfer, vol. 63, pp. 425-433, 2013.

[26] Wei, J.J., Experimental study on enhanced boiling heat transfer from silicon chips with micro-pin-fins and submicro-scale roughness, PhD thesis, Kyushu University, 2002.

[27] Rainey, K. N., Pool and flow boiling heat transfer from microporous flat and finned surfaces in FC-72, Ph.D. thesis, The University of Texas at Arlington, Arlington, TX, 2001.

[28] Antar, B.N., Nuotio-Antar, V.S., Fundamentals of low gravity fluid dynamics and heat 
transfer, CRC press, Boca Raton, FL, 1993.

[29]Ohta, H., Kawasaki, K., Okada, S., Azuma, H., Kakehi, K., Morita, T.S., Nucleate pool boiling heat transfer under reduced gravity condition, Microgravity Quartery, vol. 6, no. 2-3, pp. 114-120, 1996.

[30] Straub, J., Boiling heat transfer and bubble dynamics in microgravity, Advance in Heat Transfer, vol. 35, pp. 57-172, 2001.

[31]Di Marco, P., and Grassi, W., Effects of external electric field on pool boiling: Comparison of terrestrial and microgravity data in the ARIEL experiment, Experimental Thermal and Fluid Science, vol. 35, no. 5, pp. 780-787, 2011.

[32] VDI Heat Atlas, Ed., Verein Deutscher Ingenieure, (English version), VDI-Verlag, Dusseldorf, 1993.

[33]Di Marco, P., and Grassi, W., Effect of force fields on pool boiling flow patterns in normal and reduced gravity, Heat and Mass Transfer, vol.45, no. 7, pp. 959-966, 2009.

[34] Asano, H., Akita, K., and Inoue, M., Effect of gravity on pool boiling heat transfer on thermal spray coating, Microgravity Science and Technology, vol. 19, no. 3-4, pp. 90-92, 2007.

[35]Zell, M., Straub, J., and Weinzierl, A., Nucleate pool boiling in subcooled liquid under microgravity results of texus experimental investigations, Proc. 5th European Symposium on Material Sciences under Microgravity, Schloss Elmau, Germany, pp.327-333, 1984. 


\section{ACCEPTED MANUSCRIPT}

[36] Oka, T., Abe, Y., Mori, Y. H., and Nagashima, A., Pool boiling heat transfer in microgravity (experiments with CFC-113 and water utilizing a drop shaft facility). JSME International Journal Series B-Fluids and Thermal Engineering, vol. 39, no. 4, pp. 798-807, 1996.

[37]Zhang, Y. H., Wei, J. J., Xue, Y. F., Kong, X., Zhao. J.F., Bubble dynamics in nucleate pool boiling on micro-pin-finned surfaces in microgravity, Applied Thermal Engineering, vol. 70, no. 1, pp. 172-182, 2014. 
Table 1 Experimental conditions of the smooth surface in microgravity

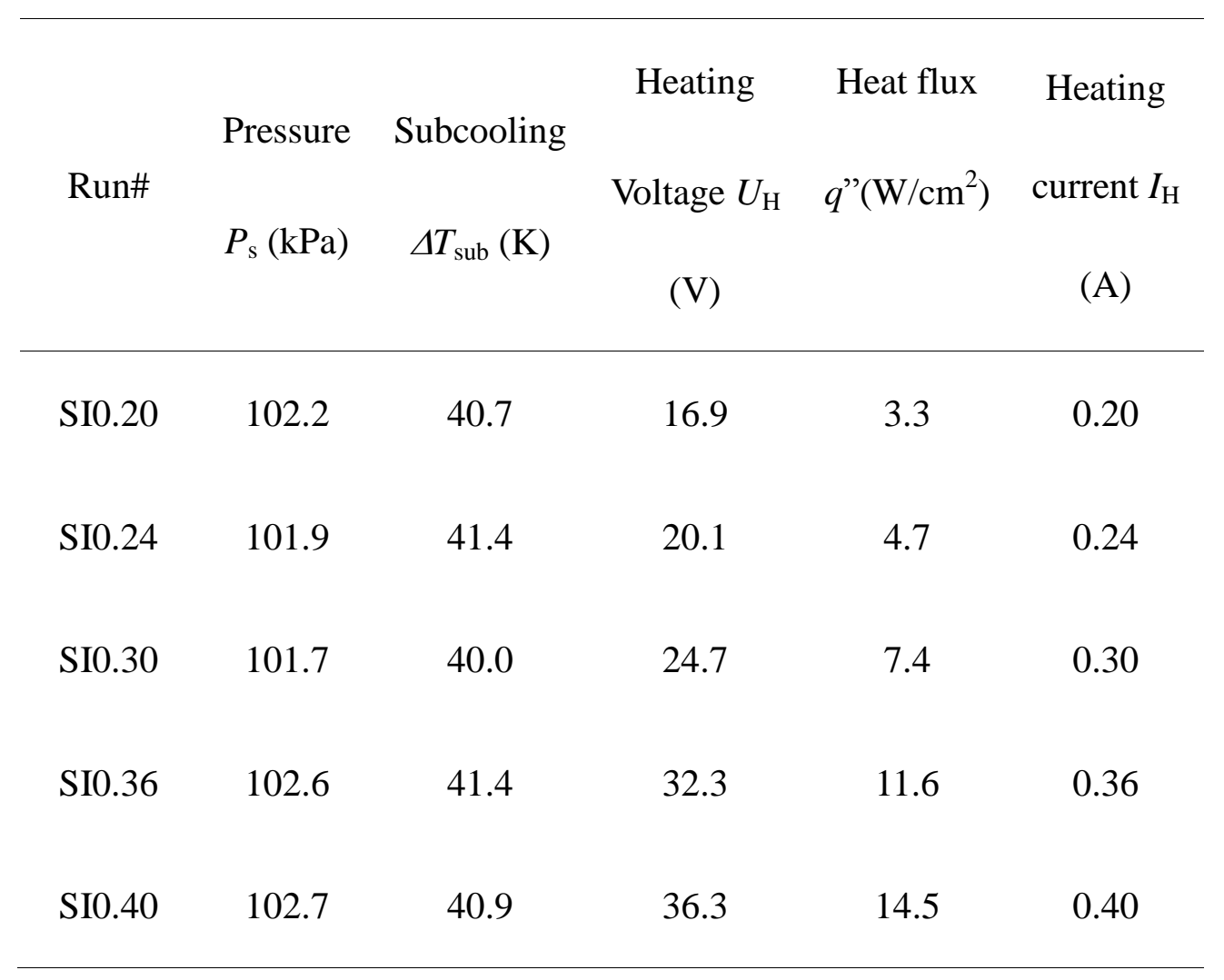


Table 2 Experimental conditions of chip PF30-60 in microgravity

\begin{tabular}{|c|c|c|c|c|c|}
\hline \multirow{5}{*}{ Run\# } & \multirow{5}{*}{$\begin{array}{l}\text { Pressure } \\
P_{\mathrm{s}}(\mathrm{kPa})\end{array}$} & \multirow{2}{*}{\multicolumn{2}{|c|}{ Subcooling }} & \multirow{3}{*}{ Heat flux } & \multirow{3}{*}{$\begin{array}{l}\text { Heating } \\
\text { current }\end{array}$} \\
\hline & & & & & \\
\hline & & & Voltage & & \\
\hline & & $\Delta T_{\mathrm{sub}}(\mathrm{K})$ & & $q^{\prime \prime}\left(\mathrm{W} / \mathrm{cm}^{2}\right)$ & \\
\hline & & & $U_{\mathrm{H}}(\mathrm{V})$ & & $I_{\mathrm{H}}(\mathrm{A})$ \\
\hline PF3060I0.26 & 103.4 & 44.5 & 27.7 & 7.2 & 0.26 \\
\hline PF3060I0.34 & 102.9 & 42.2 & 36.9 & 12.5 & 0.34 \\
\hline PF3060I0.42 & 103.4 & 44.3 & 46.3 & 19.4 & 0.42 \\
\hline PF3060U55 & 101.7 & 30.4 & 55.0 & 27.9 & 0.51 \\
\hline PF3060U60 & 100.7 & 32.4 & 60.0 & 33.0 & 0.55 \\
\hline PF3060U63 & 100.7 & 31.3 & 63.0 & 36.1 & 0.57 \\
\hline PF3060U66 & 100.9 & 32.1 & 66.0 & 39.5 & 0.60 \\
\hline PF3060U70 & 100.9 & 27.2 & 70.0 & 43.6 & 0.62 \\
\hline
\end{tabular}


Table 3 Experimental conditions of chip PF50-120 in microgravity

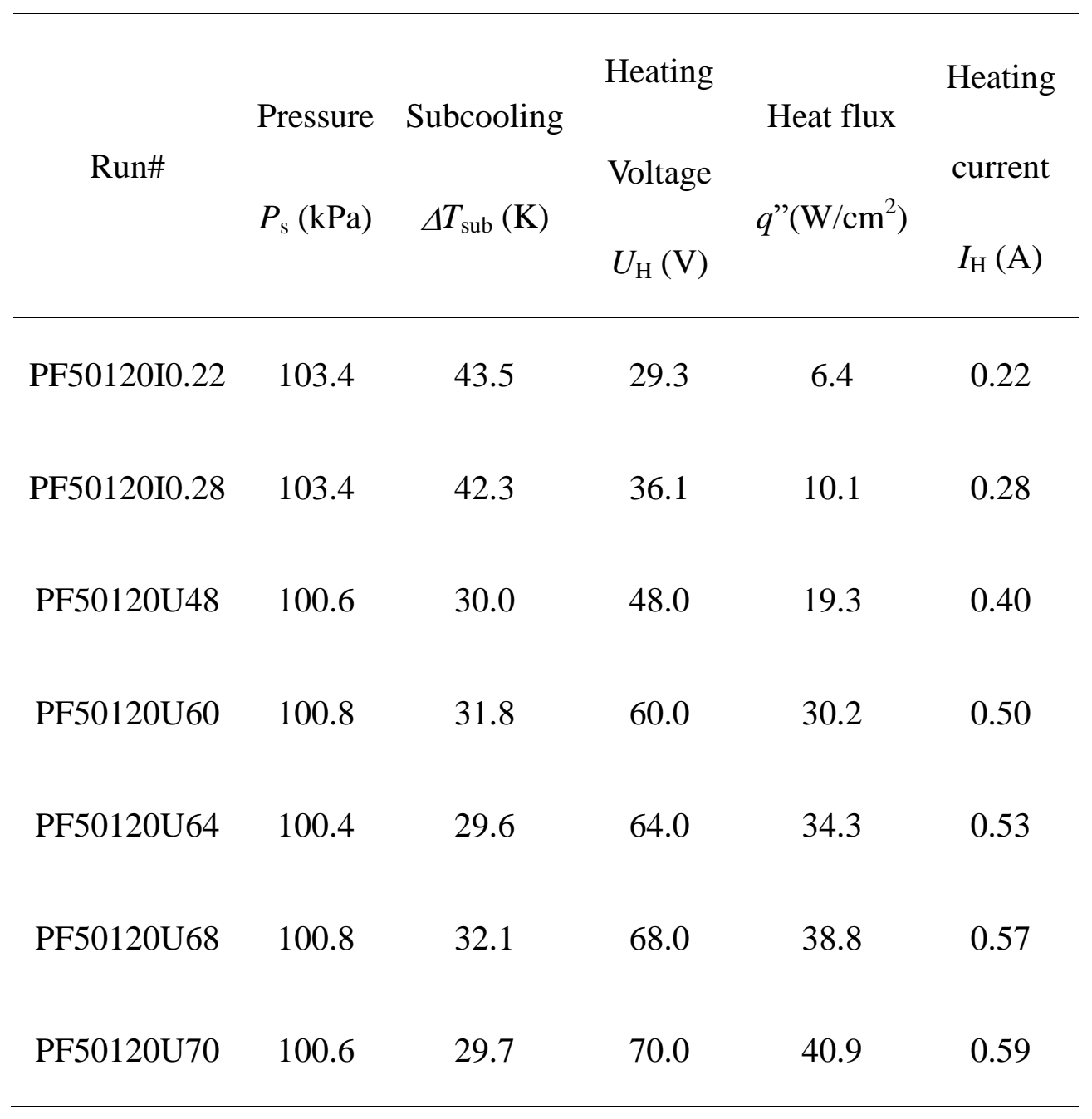


Table 4 Pool boiling in microgravity: main features of the flat plate heater experimental activities

Legend: OF: orbital flight; SR: sounding rocket; PF: parabolic flight; DT: drop tower/drop shaft.

\begin{tabular}{|c|c|c|c|c|c|c|c|}
\hline Author & Heater/facility & Fluid & $\begin{array}{l}P_{\mathrm{s}} \\
(\mathrm{kPa} \\
)\end{array}$ & $\begin{array}{l}\Delta T_{\mathrm{sub}} \\
(\mathrm{K})\end{array}$ & $\begin{array}{l}q^{\prime \prime} \mathrm{CHF}- \\
\mu g \\
(\mathrm{~W} / \mathrm{c} \\
\left.\mathrm{m}^{2}\right)\end{array}$ & $\begin{array}{c}q " \mathrm{CHF}- \\
\mu g / \\
q " \mathrm{CHF}- \\
1 g\end{array}$ & $g / g_{0}$ \\
\hline $\begin{array}{l}\text { Zell et } \\
\text { al. [35] }\end{array}$ & $\begin{array}{l}\text { Gold film Flat plate: } 20 \\
\mathrm{~mm} \times 40 \mathrm{~mm} / \mathrm{SR}\end{array}$ & R113 & 1 & 17 & 4 & $53 \%$ & $10^{-4}$ \\
\hline $\begin{array}{l}\text { Oka et } \\
\text { al. [36] }\end{array}$ & $\begin{array}{l}\text { ITO film flat plate: } 30 \\
\mathrm{~mm} \times 30 \mathrm{~mm} / \mathrm{DT}\end{array}$ & CFC-113 & 1 & $\begin{array}{c}0 \\
6-9\end{array}$ & $\begin{array}{l}4.48 \\
7.2\end{array}$ & $\begin{array}{l}31 \% \\
68 \%\end{array}$ & $10^{-5}$ \\
\hline $\begin{array}{l}\text { Lee et } \\
\text { al., [1] }\end{array}$ & $\begin{array}{l}\text { Gold film flat } \\
\text { plate:19.05×38.1 } \\
\mathrm{mm}^{2} / \mathrm{OF}\end{array}$ & $\mathrm{R}-113$ & $\begin{array}{l}106 . \\
9-15 \\
6.5\end{array}$ & $0-11$ & $4-6$ & $\begin{array}{c}\text { About } \\
1 / 3\end{array}$ & $10^{-4}$ \\
\hline $\begin{array}{l}\text { Kim et } \\
\text { al., [2] }\end{array}$ & $\begin{array}{l}\text { Flat heater array: } 2.7 \\
\mathrm{~mm} \times 2.7 \mathrm{~mm} / \mathrm{PF}\end{array}$ & FC-72 & $\begin{array}{l}103 \\
101\end{array}$ & $\begin{array}{l}25.4 \\
32.6\end{array}$ & $\begin{array}{l}9.6 \\
10.5 \\
22.2\end{array}$ & $\begin{array}{l}47 \% \\
46 \% \\
79 \%\end{array}$ & $10^{-2}$ \\
\hline Zhao et & The multi-layer alloy & FC-72 & 90.8 & 36.9 & $8.3-10$ & About & $10^{-3}-$ \\
\hline
\end{tabular}




\begin{tabular}{|c|c|c|c|c|c|c|c|}
\hline al. & film flat plate heater: 15 & & & & 0 & $1 / 3$ & $10^{-5}$ \\
\hline \multirow[t]{3}{*}[3]{} & $\times 15 \mathrm{~mm}^{2} / \mathrm{OF}$ & & & & & & \\
\hline & Flat heater array: 4.2 & & & 11 & 6.5 & $49 \%$ & \\
\hline & $\mathrm{mm} \times 4.2 \mathrm{~mm} / \mathrm{OF}$ & & & 26 & 10.7 & $53 \%$ & \\
\hline Raj et al. & Flat heater array: 5.6 & & 1 & 11 & 5.9 & $45 \%$ & $<10^{-}$ \\
\hline \multirow[t]{8}{*}[6]{} & $\mathrm{mm} \times 5.6 \mathrm{~mm} / \mathrm{OF}$ & & atm & 26 & 9.5 & $47 \%$ & 6 \\
\hline & Flat heater array: 7.0 & & & 11 & 4.5 & $34 \%$ & \\
\hline & $\mathrm{mm} \times 7.0 \mathrm{~mm} / \mathrm{OF}$ & & & 26 & 8.7 & $43 \%$ & \\
\hline & Smooth & & & & & & \\
\hline & & & & $40.7-41$ & $11.8-14$ & & \\
\hline & surface:10 & & & & & $40-50 \%$ & \\
\hline & $\mathrm{mm}^{2} / \mathrm{DT}[24]$ & & & .4 & .5 & & \\
\hline & Micro-pin-fins: $10 \times 10$ & & & $30.4-44$ & $39.1-43$ & & \\
\hline \multirow[t]{2}{*}{ Wei's } & & & 1 & & & $72-80 \%$ & $<10$ \\
\hline & $\mathrm{mm}^{2}, \mathrm{PF} 30-60 / \mathrm{DT}$ [25] & FC-72 & & .5 & .6 & & \\
\hline \multirow[t]{6}{*}{ Group } & & & atm & & & & 2 \\
\hline & Micro-pin-fins: $10 \times 10$ & & & & & & \\
\hline & & & & $29.7-43$ & 40.9(ne & About & \\
\hline & & & & .5 & ar & $67 \%$ & \\
\hline & PF50-120/DT(Present ) & & & & & & \\
\hline & & & & & $\mathrm{CHF})$ & & \\
\hline
\end{tabular}




\section{ACCEPTED MANUSCRIPT}

Table 5 Parameters of micro-pin-fins

\begin{tabular}{ccccccc}
\hline & & Fin & Fin & & & Surface area \\
Fhips & Fin width & & & Fin pitch & & \\
& $w(\mu \mathrm{m})$ & thickness & height & & $h / p$ & enhancement \\
& & $t(\mu \mathrm{m})$ & $h(\mu \mathrm{m})$ & & ratio \\
\hline PF30-60 & 30 & 30 & 60 & 60 & 1.0 & 3.0 \\
PF50-120 & 50 & 50 & 120 & 100 & 1.2 & 3.4 \\
\hline
\end{tabular}




\section{List of Figure captions}

Figure 1 Schematic diagram of the experimental apparatus

Figure 2 SEM images of micro-pin-fins
(a) PF30-60
(b) PF50-120

Figure 3 Nucleate boiling heat transfer coefficient and heat flux of micro-pin-fins under different gravity levels

Figure 4 Heat transfer coefficient of micro-pin-finned surfaces under different gravity levels

Figure 5 Comparisons of pool boiling curves of FC-72 on chip S and micro-pin-fins of the present results with other data reported in the literature

Figure 6 Comparison of our previous experimental data [26] with those of O'connor et al. [9] for a smooth surface

Figure 7 Bubble behavior under different gravity level for chip $S$ at $I_{\mathrm{H}}=0.4 \mathrm{~A}, \mathrm{PF} 30-60$ and PF50-120 both at $U_{\mathrm{H}}=70 \mathrm{~V}$

Figure 8 Variations of the surface temperature, heat voltage and gravity for chip $\mathrm{S}$ at $I_{\mathrm{H}}=0.4 \mathrm{~A}$, PF30-60 and PF50-120 both at $U_{\mathrm{H}}=70 \mathrm{~V}$

Figure 9 Boiling curves for chips $\mathrm{S}$ and micro-pin-fins under different gravity levels

Figure 10 Bubble behaviors in normal gravity and microgravity at low heat fluxes: (a) Chip S, $q "=11.6 \mathrm{~W} / \mathrm{cm}^{2}$, (b) PF30-60, $q "=12.5 \mathrm{~W} / \mathrm{cm}^{2}$, (c) PF50-120, $q "=10.1 \mathrm{~W} / \mathrm{cm}^{2}$

Figure 11 Bubble behaviors in normal gravity and microgravity at moderate and high heat fluxes: 
(a) PF30-60, $q "=27.9 \mathrm{~W} / \mathrm{cm}^{2}$, (b) PF50-120, $q "=30.2 \mathrm{~W} / \mathrm{cm}^{2}$, (c) PF30-60, $q "=39.5 \mathrm{~W} / \mathrm{cm}^{2}$, (d) PF50-120, $q^{\prime \prime}=38.8 \mathrm{~W} / \mathrm{cm}^{2}$

Figure 12 Bulk liquid supply and micro-convection caused by capillary force

Figure 13 (a) Bubble behavior before departure of micro-pin-fins (b) Schematic diagram of the mechanism of thermocapillary flow

Figure 14 Boiling phenomenon and mechanism schematic diagram of large bubble coalescence in vertical direction 


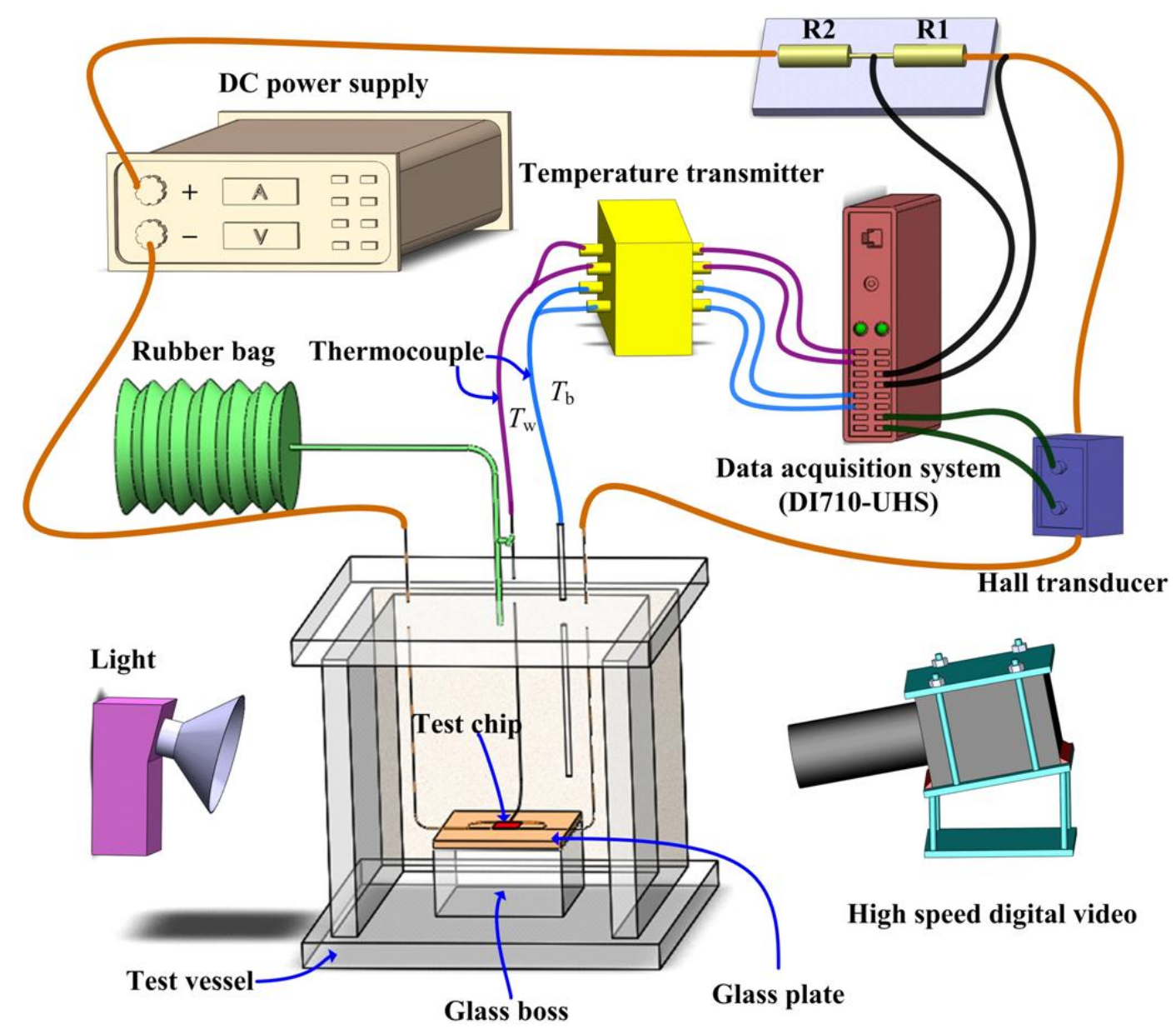

Figure 1 Schematic diagram of the experimental apparatus 


\section{ACCEPTED MANUSCRIPT}

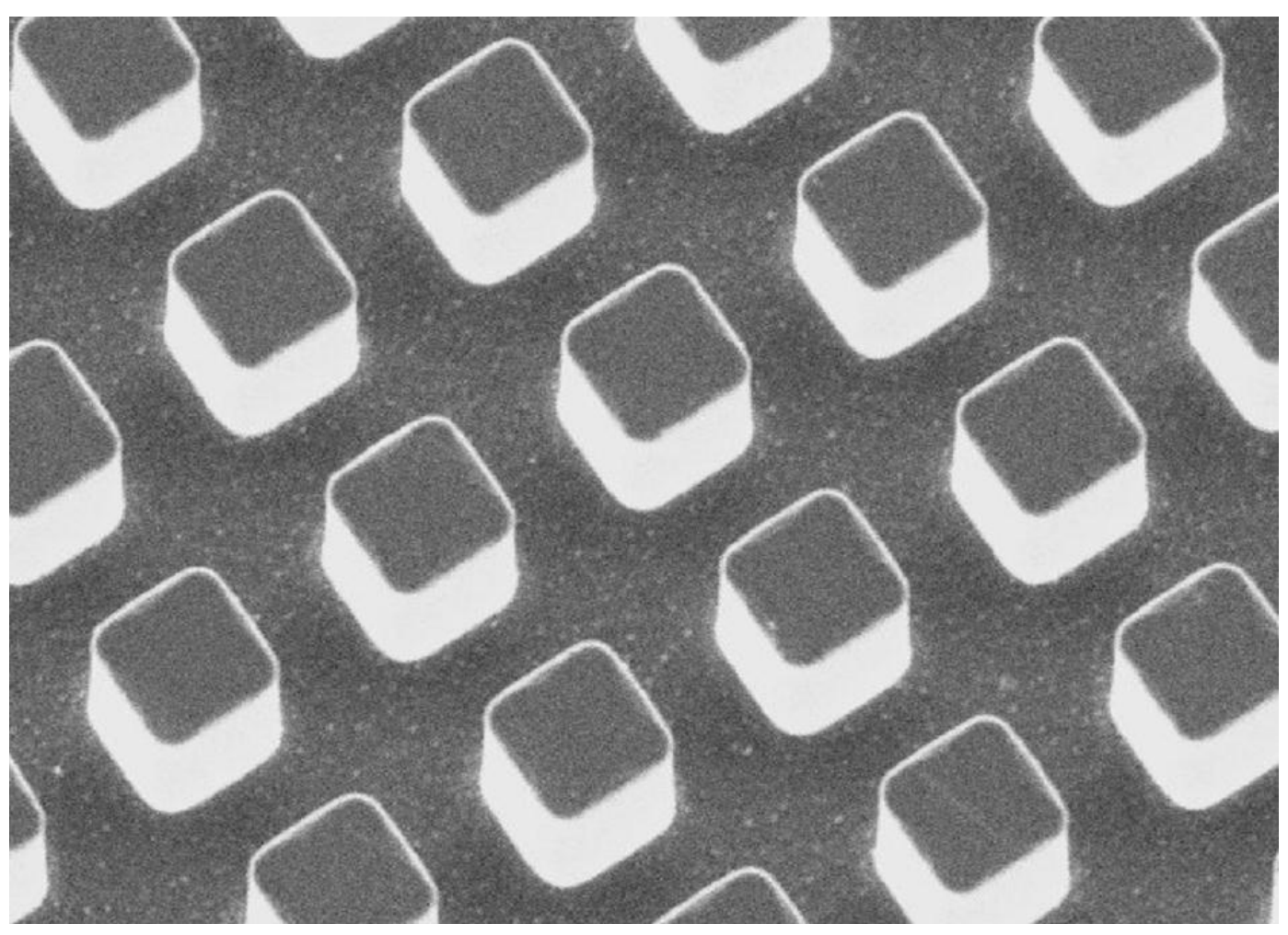

(a) PF30-60 


\section{ACCEPTED MANUSCRIPT}

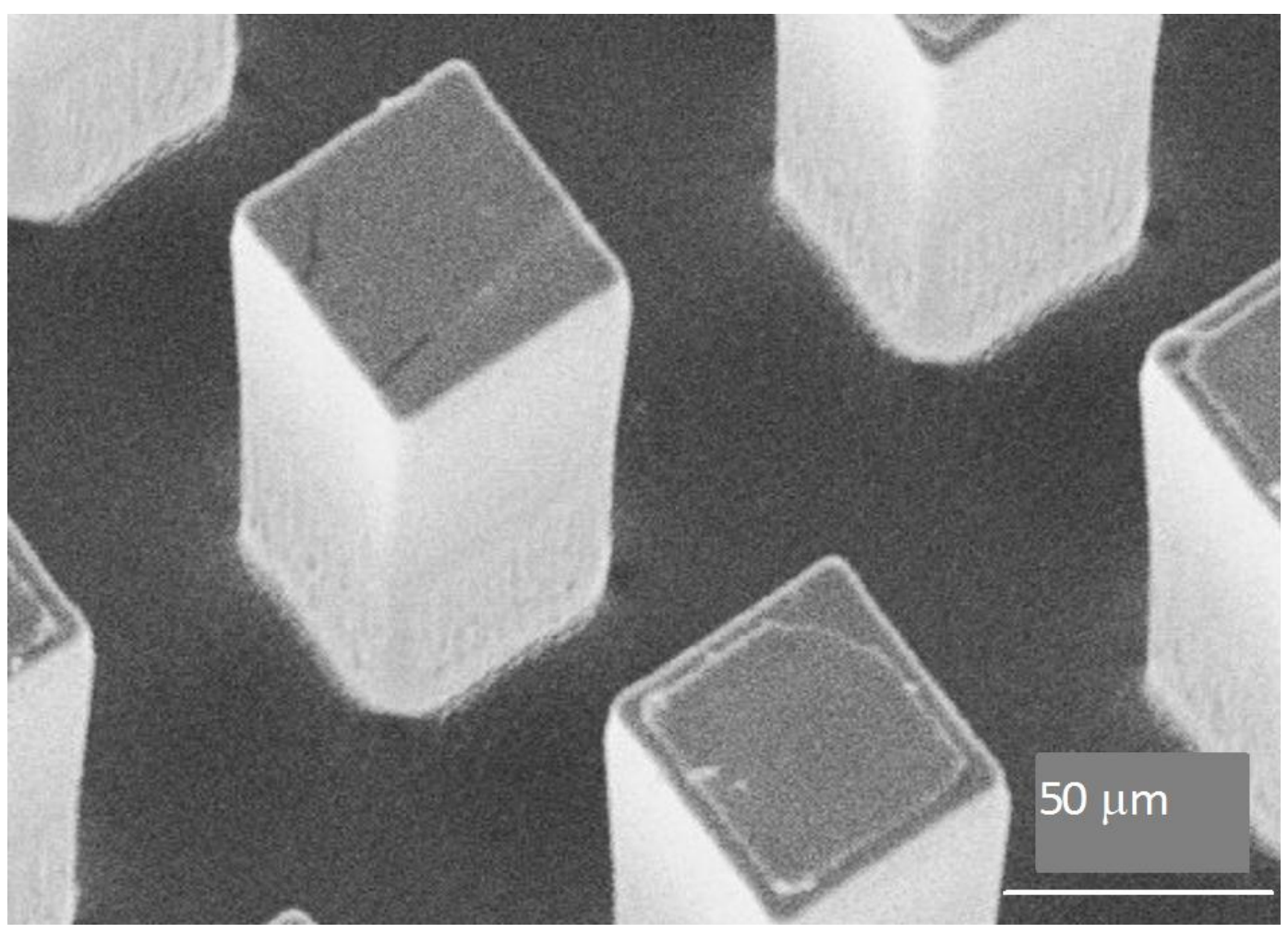

(b) PF50-120

Figure 2 SEM images of micro-pin-fins 

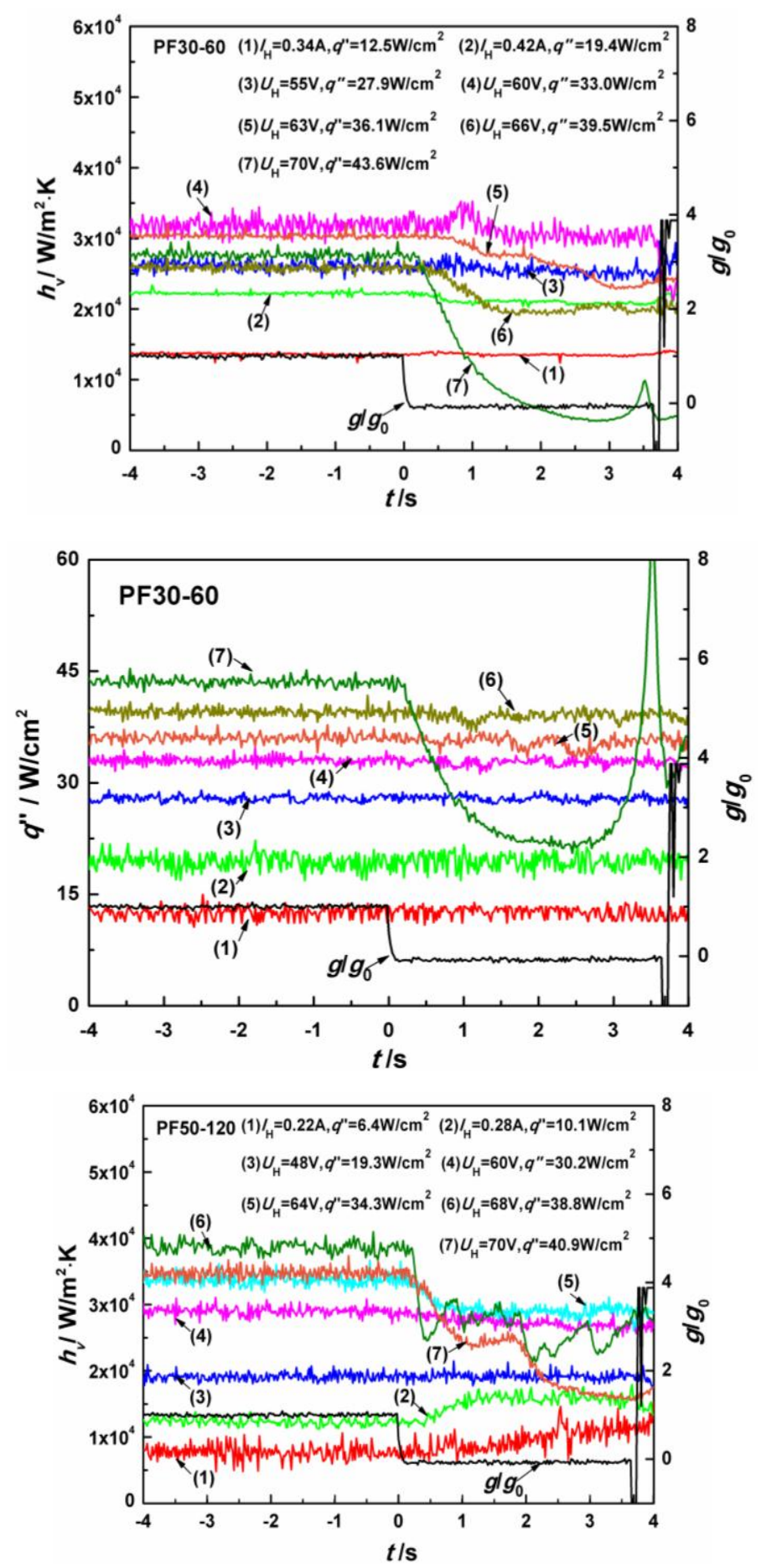

Figure 3 (continued on the next page) 


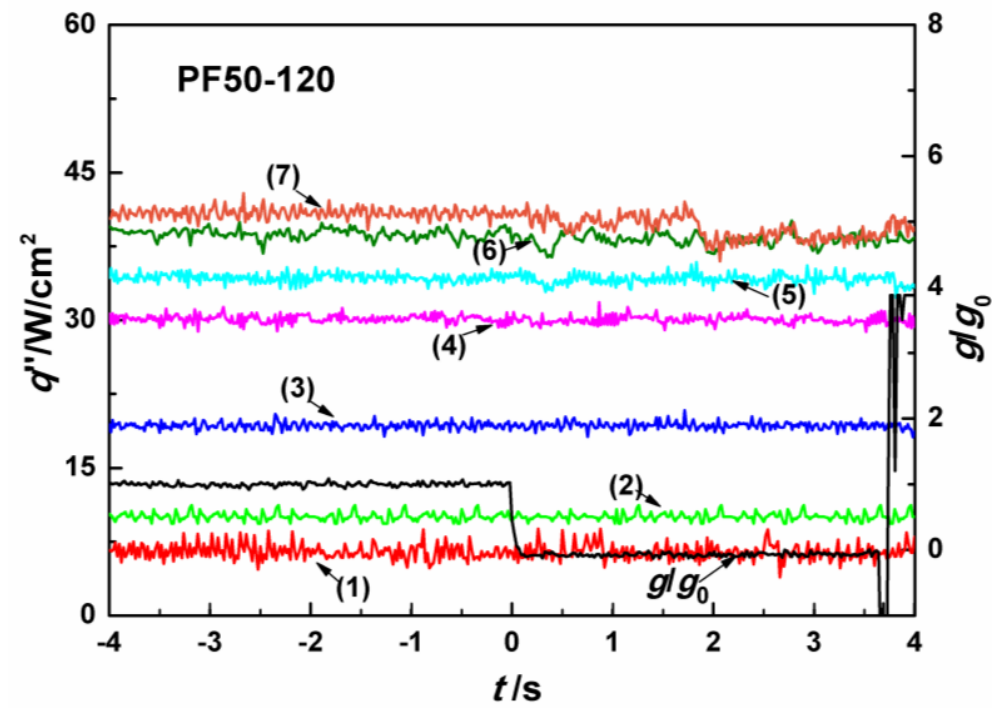

Figure 3 Nucleate boiling heat transfer coefficient and heat flux of micro-pin-fins under different gravity levels 


\section{ACCEPTED MANUSCRIPT}

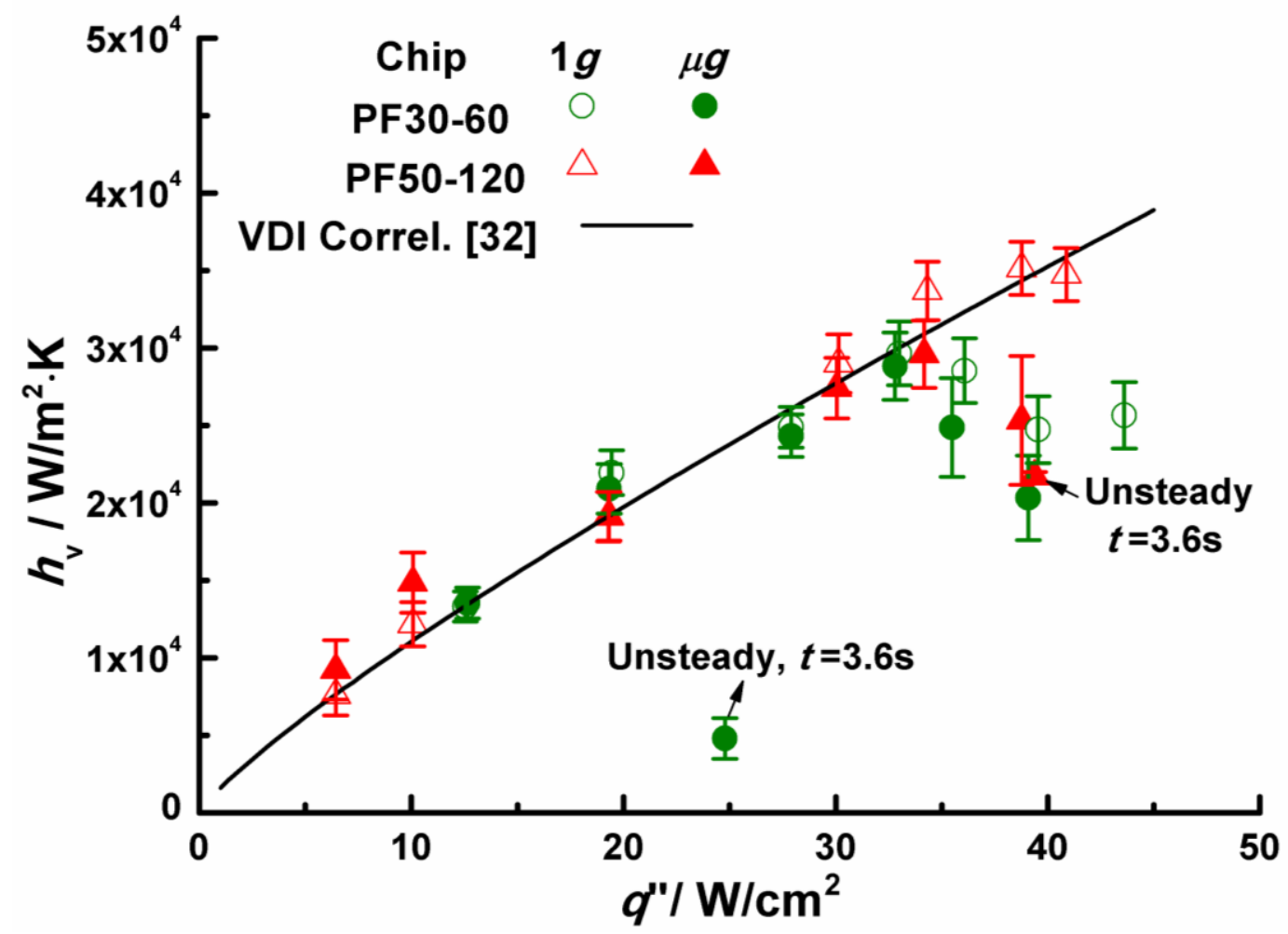

Figure 4 Heat transfer coefficient of micro-pin-finned surfaces under different gravity levels 


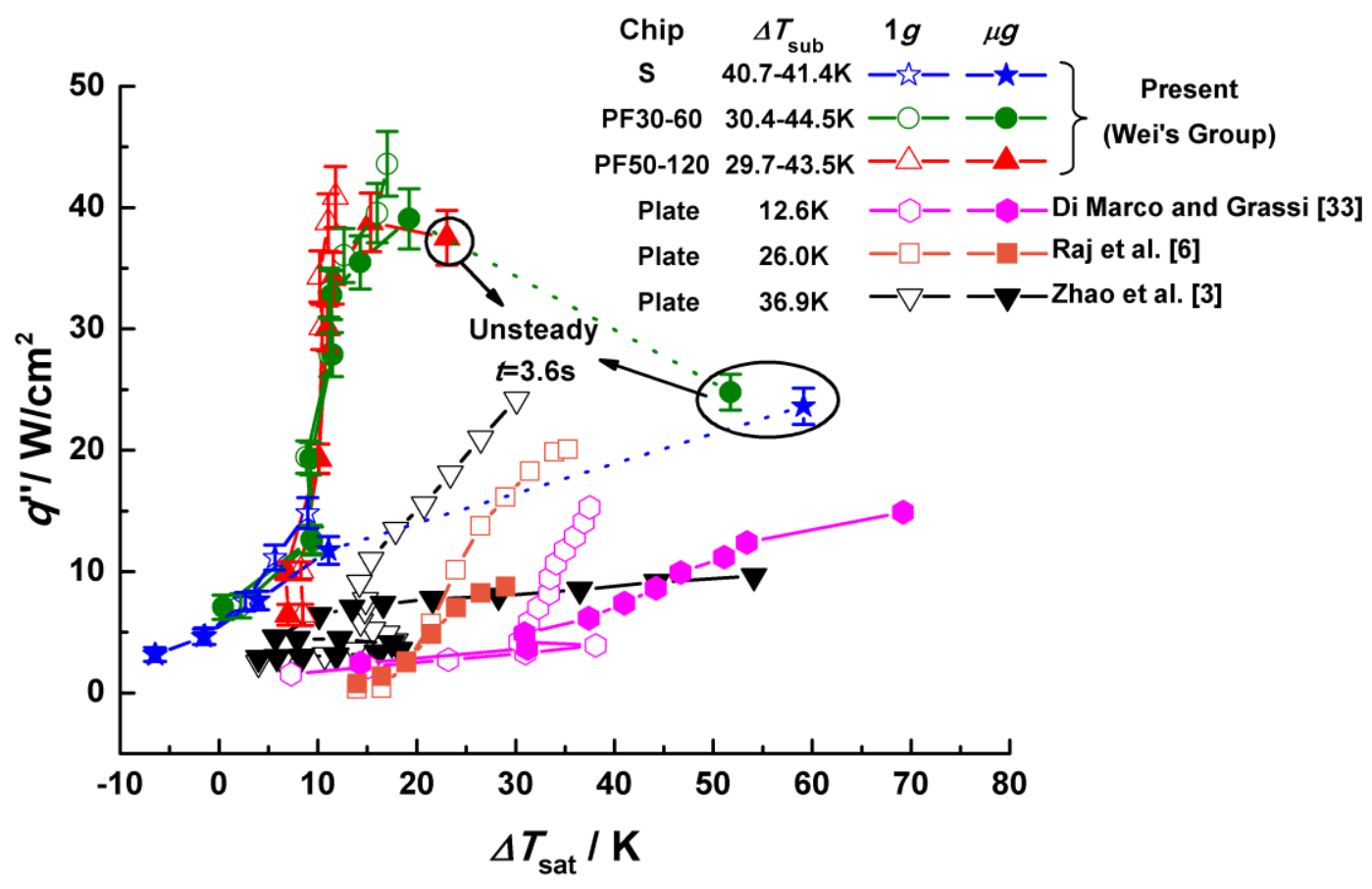

Figure 5 Comparisons of pool boiling curves of FC-72 on chip S and micro-pin-fins of the present results with other data reported in the literature 


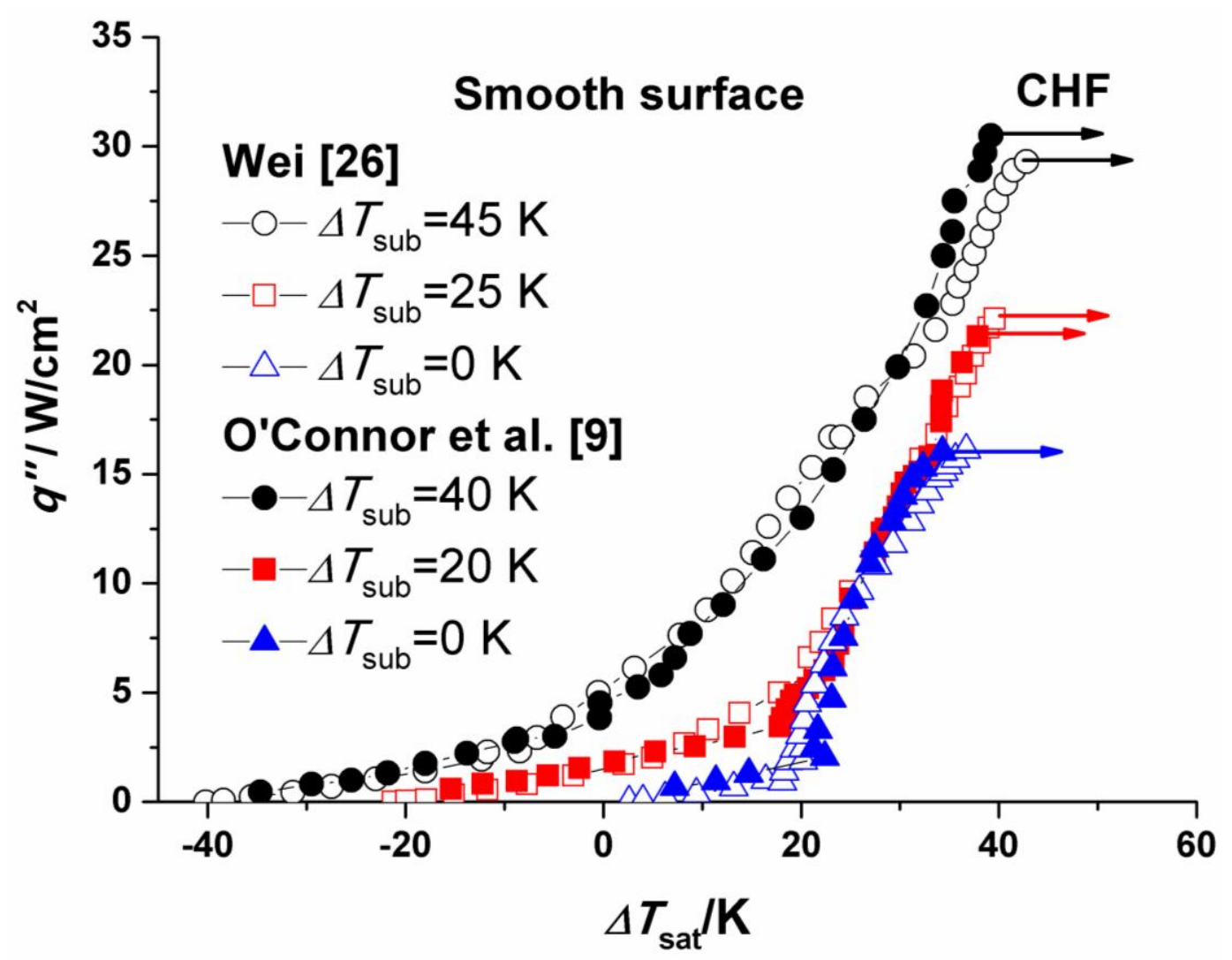

Figure 6 Comparison of our previous experimental data [26] with those of O'connor et al. [9] for a smooth surface 


\section{ACCEPTED MANUSCRIPT}

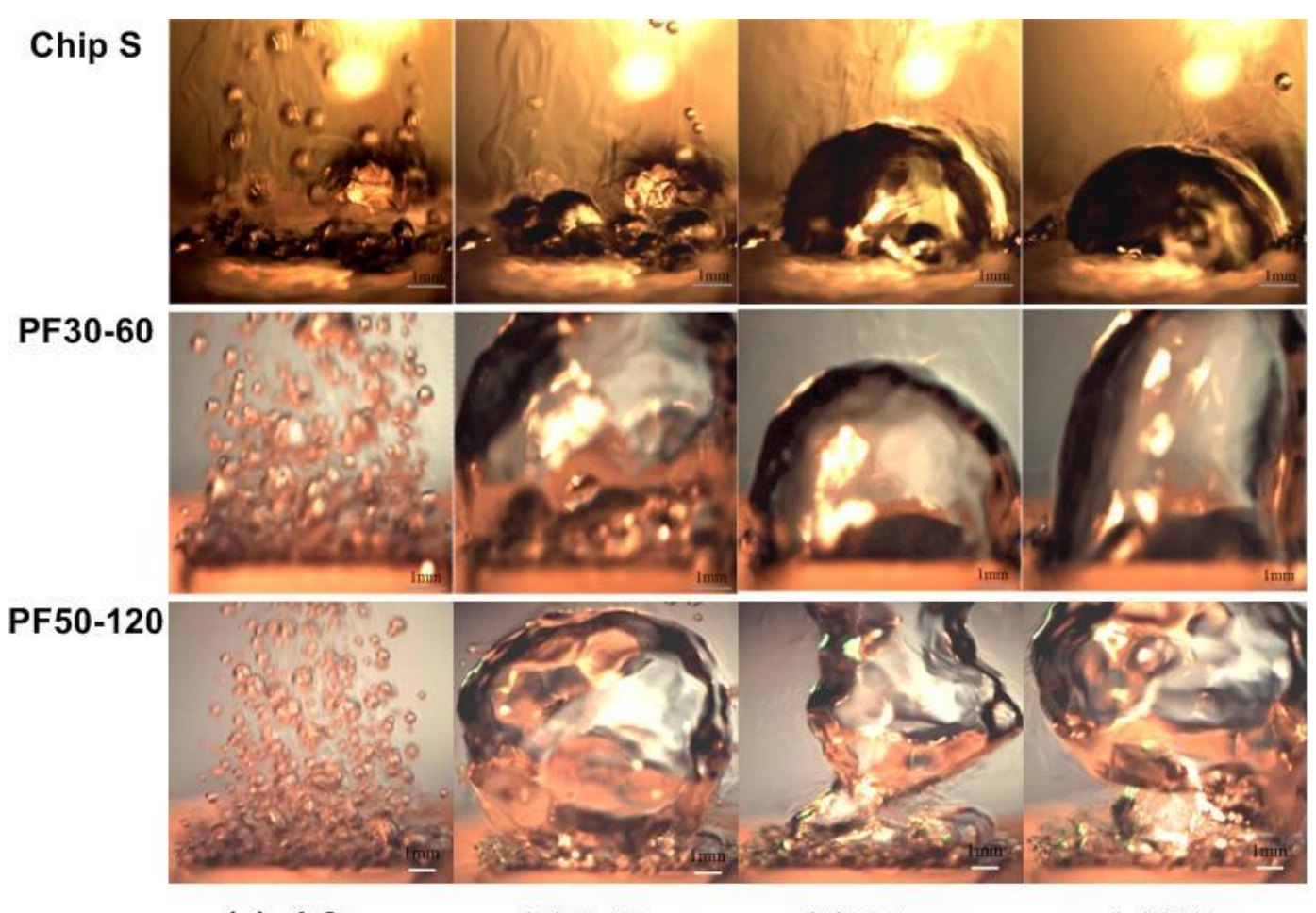
(a) $-1.0 \mathrm{~s}$
(b) $0.12 \mathrm{~s}$
(c) $1.6 \mathrm{~s}$
(d) $3.0 \mathrm{~s}$

Figure 7 Bubble behavior under different gravity level for chip S at $I_{\mathrm{H}}=0.4 \mathrm{~A}, \mathrm{PF} 30-60$ and PF50-120 both at $U_{\mathrm{H}}=70 \mathrm{~V}$ 

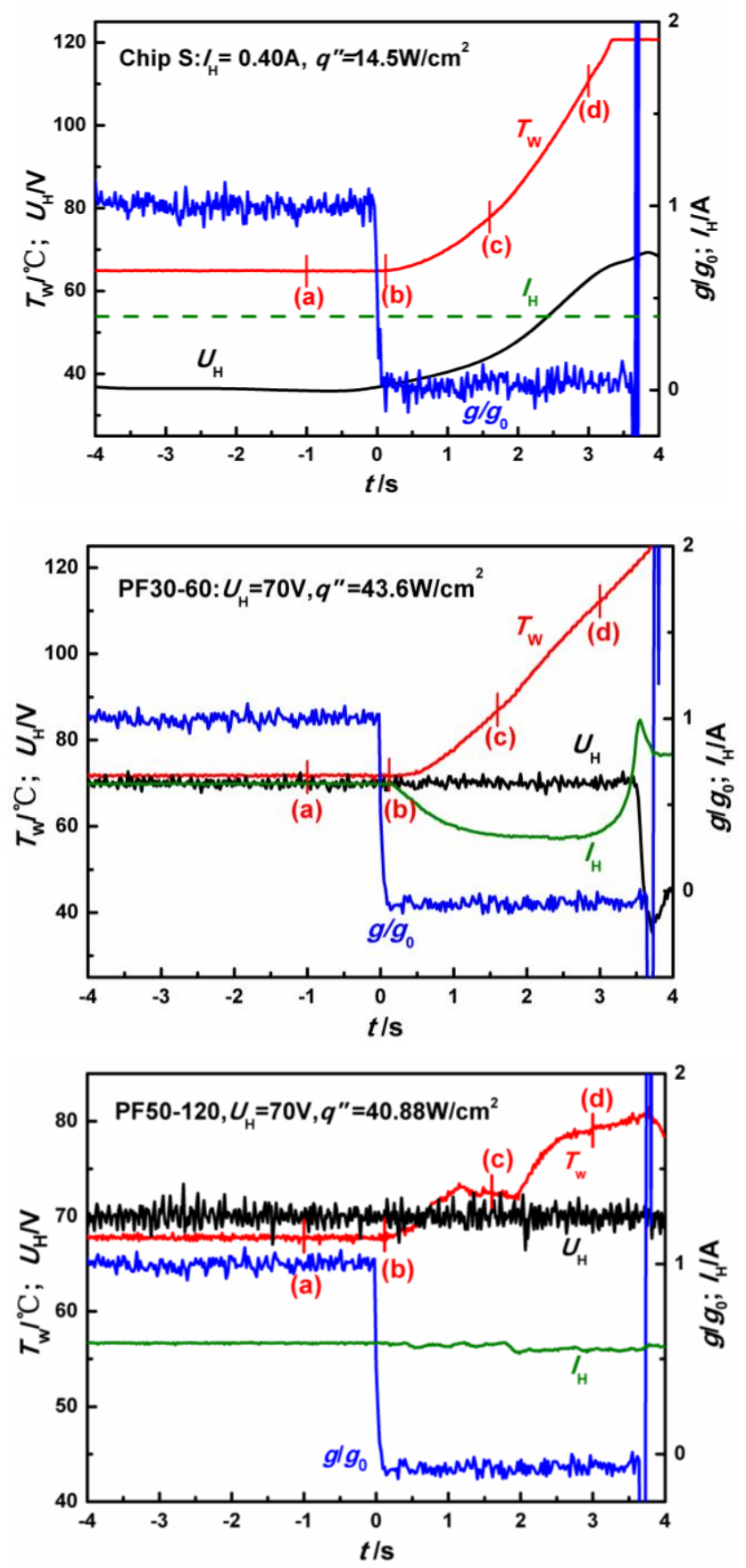

Figure 8 Variations of the surface temperature, heat voltage and gravity for chip $\mathrm{S}$ at $I_{\mathrm{H}}=0.4 \mathrm{~A}$, PF30-60 and PF50-120 both at $U_{\mathrm{H}}=70 \mathrm{~V}$ 


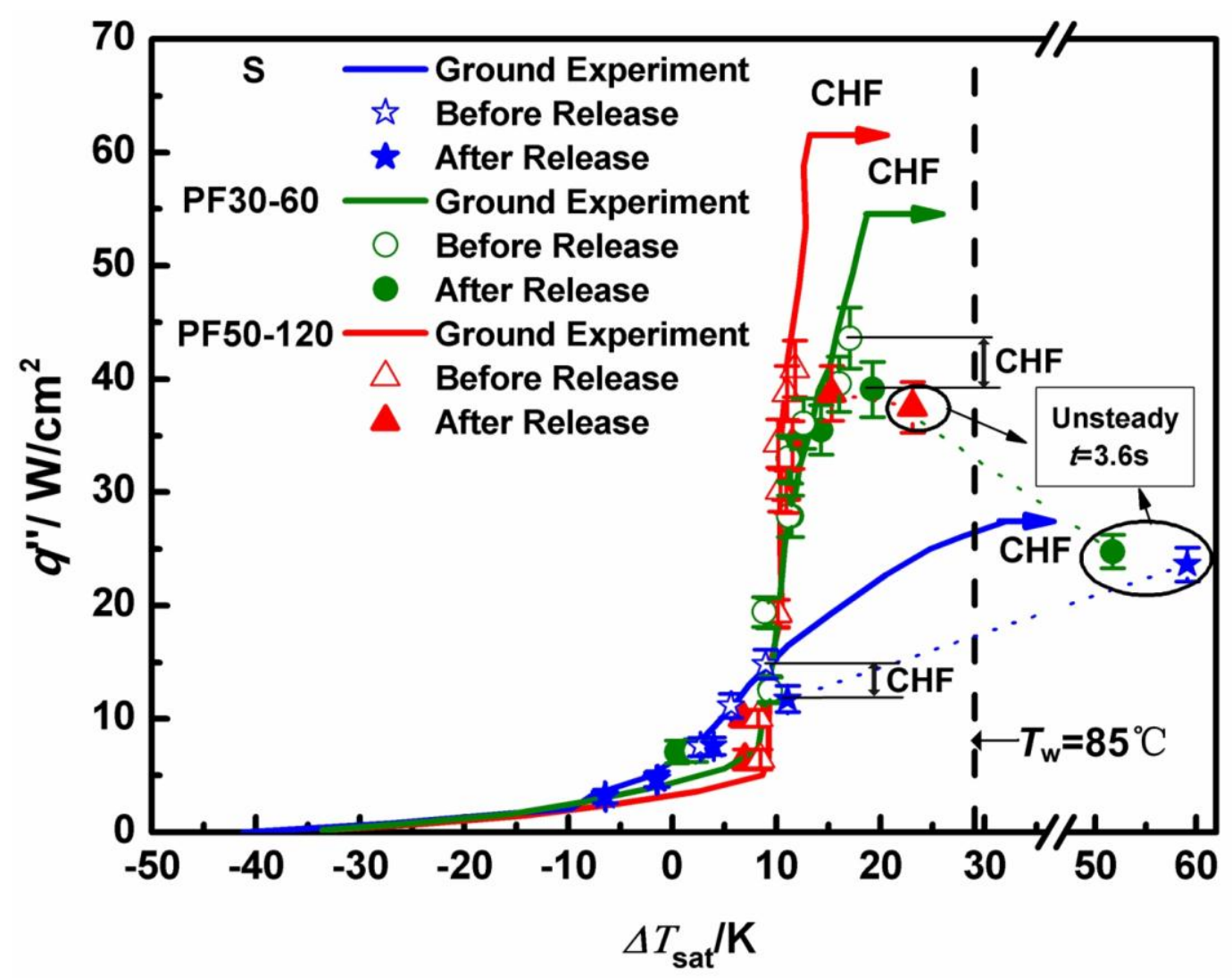

Figure 9 Boiling curves for chips S and micro-pin-fins under different gravity levels 


\section{ACCEPTED MANUSCRIPT}

(a)

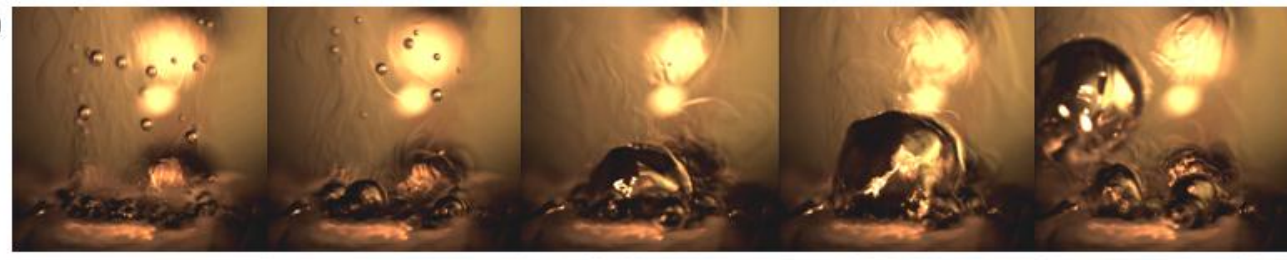

(b)

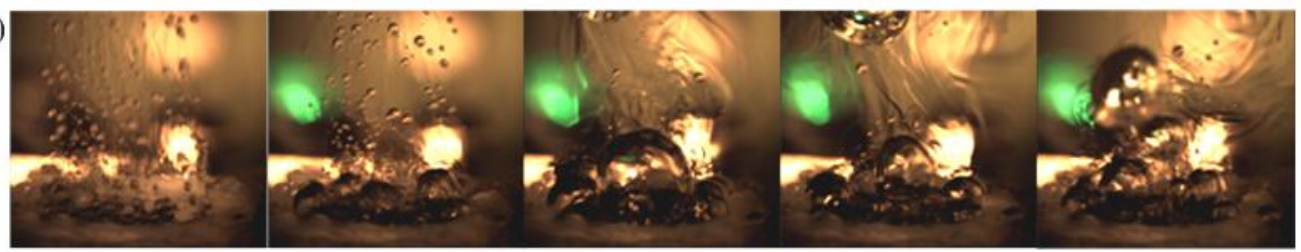

(c)

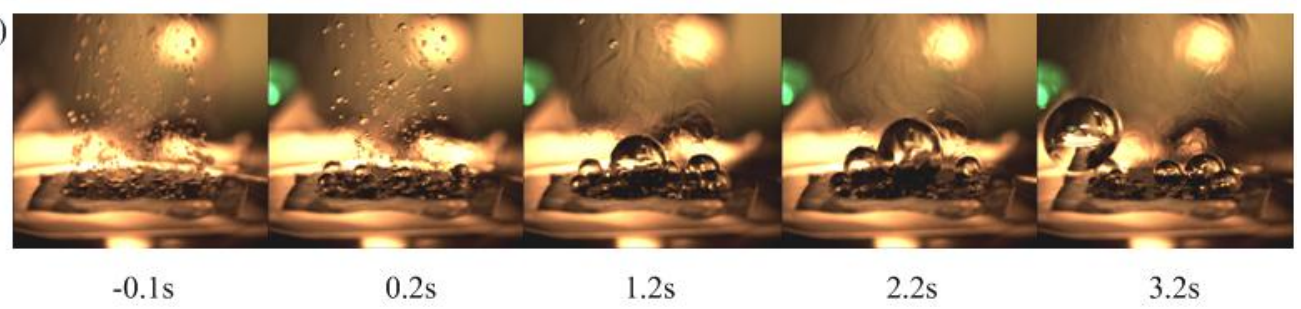

Figure 10 Bubble behaviors in normal gravity and microgravity at low heat fluxes: (a) Chip S, $q "=11.6 \mathrm{~W} / \mathrm{cm}^{2}$, (b) PF30-60, $q "=12.5 \mathrm{~W} / \mathrm{cm}^{2}$, (c) PF50-120, $q "=10.1 \mathrm{~W} / \mathrm{cm}^{2}$ 


\section{ACCEPTED MANUSCRIPT}

(a)

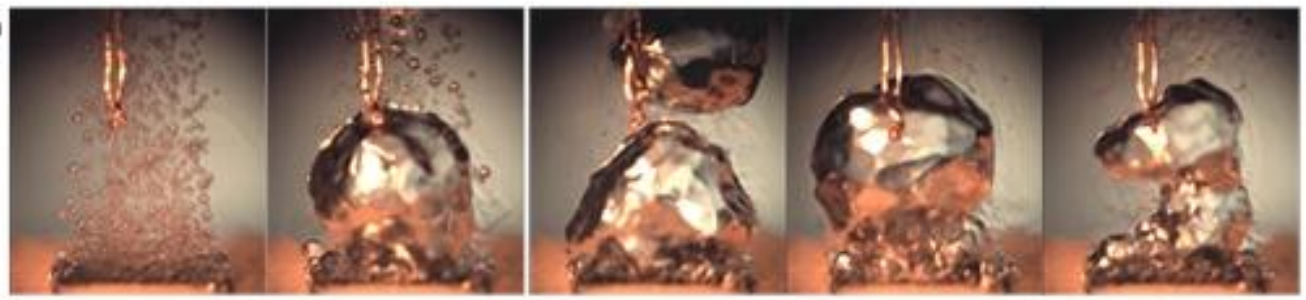

(b)

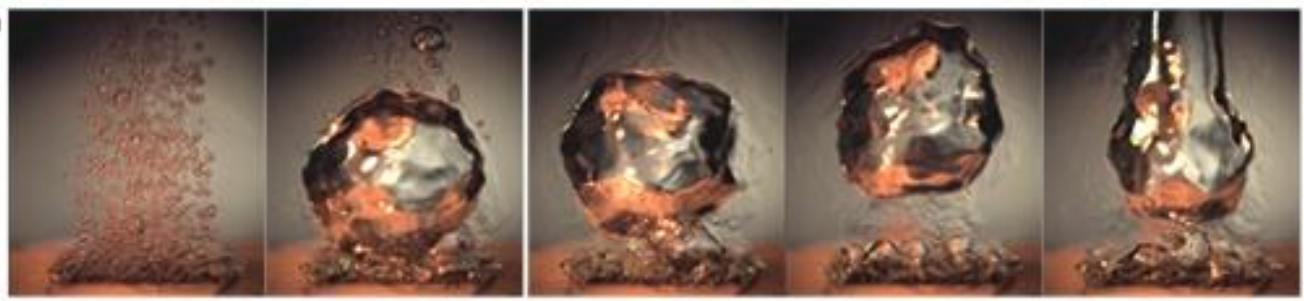

(c)

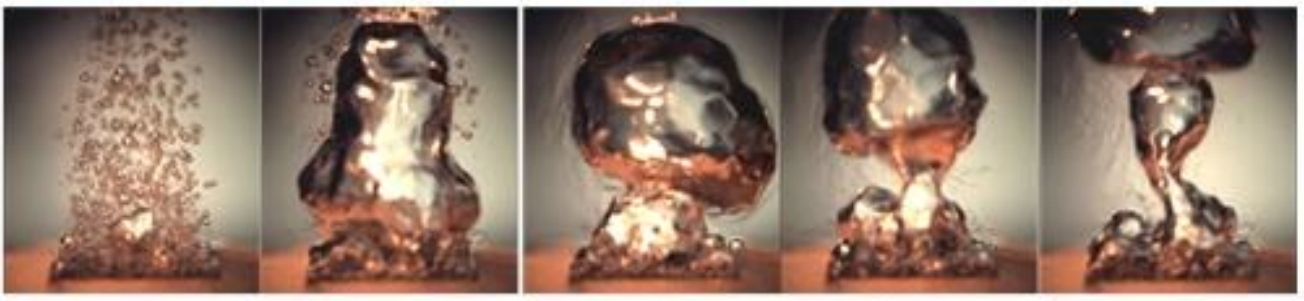

(d)

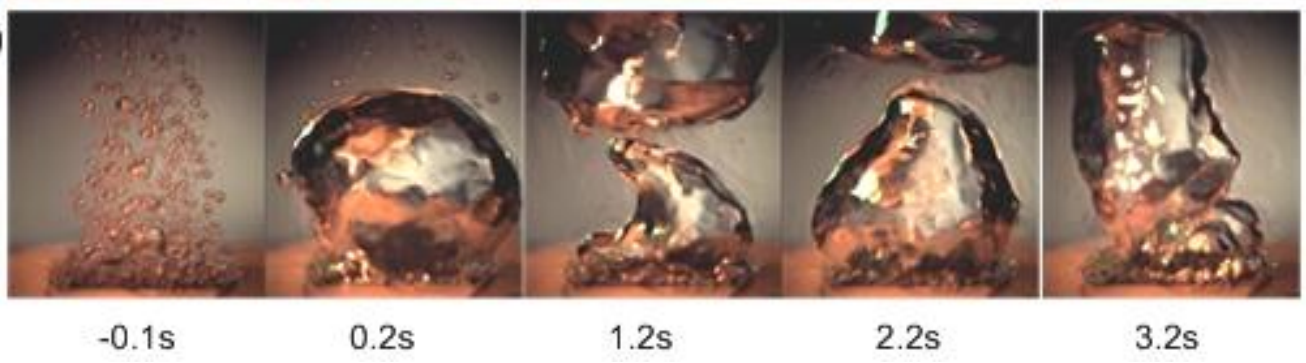

Figure 11 Bubble behaviors in normal gravity and microgravity at moderate and high heat fluxes:

(a) PF30-60, $q "=27.9 \mathrm{~W} / \mathrm{cm}^{2}$, (b) PF50-120, $q "=30.2 \mathrm{~W} / \mathrm{cm}^{2}$, (c) PF30-60, $q "=39.5 \mathrm{~W} / \mathrm{cm}^{2}$, (d) PF50-120, $q^{\prime \prime}=38.8 \mathrm{~W} / \mathrm{cm}^{2}$ 


\section{ACCEPTED MANUSCRIPT}
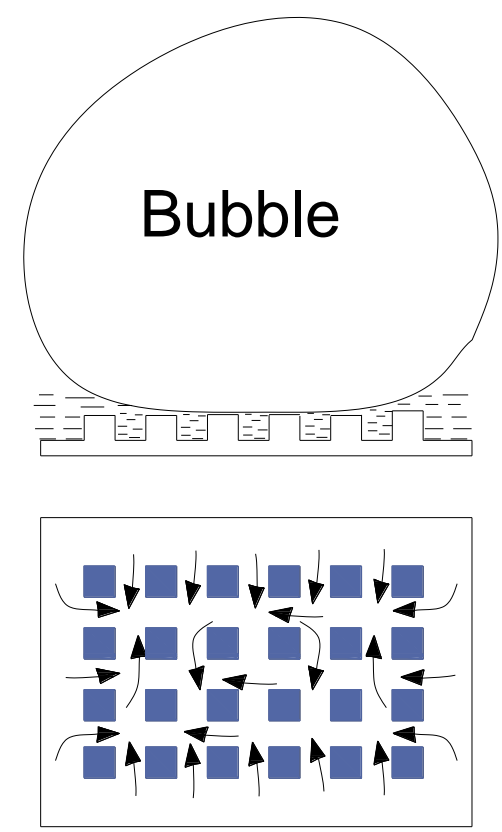

Figure 12 Bulk liquid supply and micro-convection caused by capillary force 


\section{ACCEPTED MANUSCRIPT}
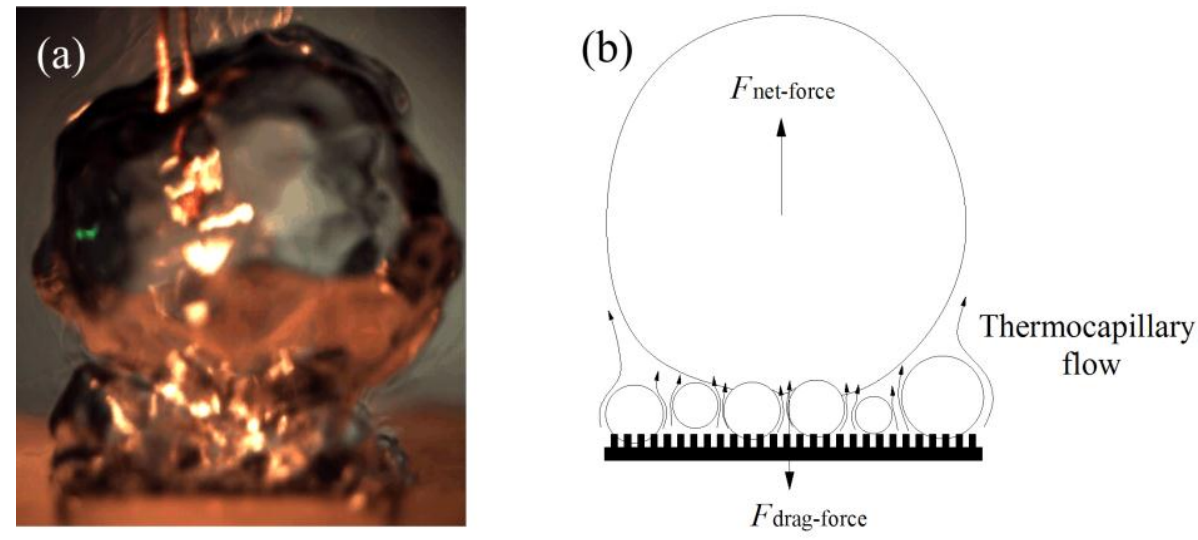

Figure 13 (a) Bubble behavior before departure of micro-pin-fins (b) Schematic diagram of the mechanism of thermocapillary flow 

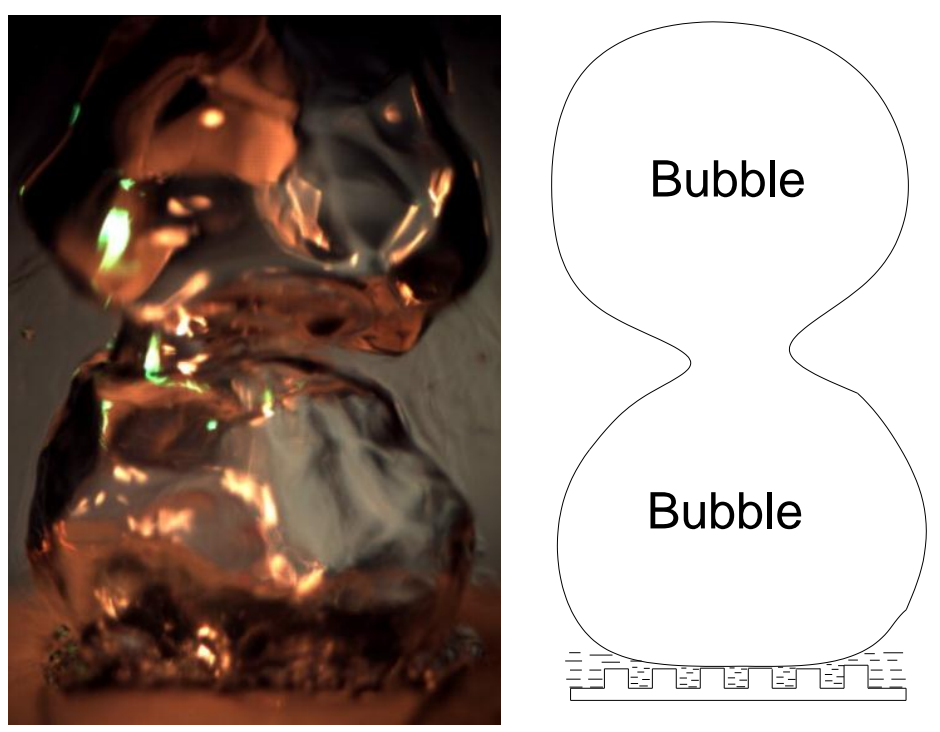

Figure 14 Boiling phenomenon and mechanism schematic diagram of large bubble coalescence in vertical direction 


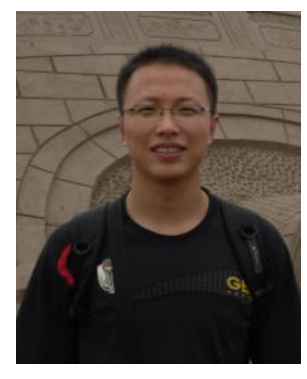

Yonghai Zhang received his Ph.D. at the State Key Laboratory of Multiphase Flow in Power Engineering in 2014 from Xi' an Jiaotong University. Now he is a lecturer in School of Chemical Engineering and Technology, Xi'an Jiaotong University, Xi'an, China. His research interests are enhanced boiling heat transfer for high efficient cooling of electronic components in space and on the ground.

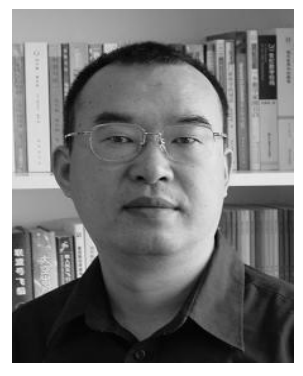

Jianfu Zhao graduated from Tsinghua University and received his B. Sc. Degree in Engineering Mechanics in 1990. He received his M.Sc. degree in Fluid Mechanics from Zhejiang University in 1993, and Ph.D. degree in Hydraulics and River Dynamics from Wuhan University of Hydraulic and Electric Engineering (presently Wuhan University School of Water Resources and Hydropower) in 1998. He is now a Professor of Key Laboratory of Microgravity (National Microgravity Laboratory) / CAS in Institute of Mechanics at Chinese Academy of Sciences, Beijing China. His current research interests include the hydrodynamics and heat-mass transfer in two-phase gas-liquid systems in microgravity. 


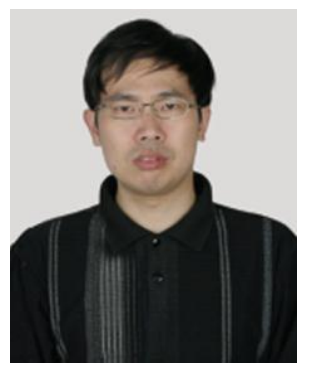

Jinjia Wei received his bachelor's degree in 1994 and Ph.D. in 1998 from Xi'an Jiaotong University. He is Vice President of School of Chemical Engineering and Technology, Xi'an Jiaotong University, Xi'an China. Besides, he is a professor of State Key Laboratory of Multi-phase Flow in Power Engineering at Xi'an Jiaotong University. His research interests are enhancement of boiling heat transfer for electronics cooling, numerical methods in fluid flow and heat transfer, drag-reduction of fluid flow, two-phase flow and heat transfer.

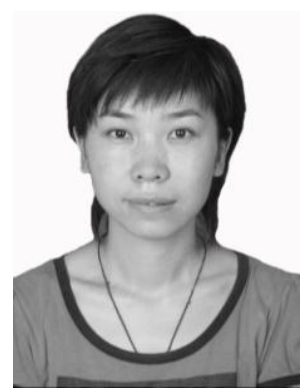

Yanfang Xue received her Ph.D. degree in 2013 from State Key Laboratory of Multiphase Flow in Power Engineering Xi'an Jiaotong University, Xi'an, China. She worked on enhanced boiling heat transfer for high-efficient cooling of electronic components in space and on the ground. 